\title{
Transcriptome, Spliceosome and Editome Expression Patterns of the Porcine Endometrium in Response to a Single Subclinical Dose of Salmonella Enteritidis Lipopolysaccharide
}

\author{
Lukasz Paukszto ${ }^{1}$, Anita Mikolajczyk ${ }^{2}$, Jan P. Jastrzebski ${ }^{1,3}{ }^{\oplus}$, Marta Majewska ${ }^{4}{ }^{\oplus}$, \\ Kamil Dobrzyn ${ }^{5}$, Marta Kiezun ${ }^{5}$, Nina Smolinska ${ }^{5}{ }^{(D)}$ and Tadeusz Kaminski ${ }^{5, *}$ \\ 1 Department of Plant Physiology, Genetics and Biotechnology, Faculty of Biology and Biotechnology, \\ University of Warmia and Mazury in Olsztyn, Oczapowskiego 1A, 10-719 Olsztyn, Poland; \\ lukasz.paukszto@uwm.edu.pl (L.P.); bioinformatyka@gmail.com (J.P.J.) \\ 2 Department of Public Health, Faculty of Health Sciences, Collegium Medicum, University of Warmia and \\ Mazury in Olsztyn, Warszawska 30, 10-082 Olsztyn, Poland; asm@uwm.edu.pl \\ 3 Bioinformatics Core Facility, Faculty of Biology and Biotechnology, University of Warmia and Mazury in \\ Olsztyn, Oczapowskiego Str 1A/113, 10-719 Olsztyn, Poland \\ 4 Department of Human Physiology and Pathophysiology, School of Medicine, Collegium Medicum, \\ University of Warmia and Mazury in Olsztyn, Warszawska Str 30, 10-082 Olsztyn, Poland; \\ marta.majewska@uwm.edu.pl \\ 5 Department of Animal Anatomy and Physiology, Faculty of Biology and Biotechnology, University of \\ Warmia and Mazury in Olsztyn, Oczapowskiego 1A, 10-719 Olsztyn, Poland; \\ kamil.dobrzyn@uwm.edu.pl (K.D.); marta.kiezun@uwm.edu.pl (M.K.); nina.smolinska@uwm.edu.pl (N.S.) \\ * Correspondence: tkam@uwm.edu.pl; Tel.: +48-89-523-44-20
}

Received: 15 May 2020; Accepted: 12 June 2020; Published: 13 June 2020

check for updates

\begin{abstract}
Endometrial infections at a young age can lead to fertility issues in adulthood. Bacterial endotoxins, such as lipopolysaccharide (LPS), can participate in long-term molecular changes even at low concentrations. Lipopolysaccharide plays a crucial role in the progression of septic shock, inflammation and auto-immune diseases. The aim of this study was to describe transcriptomic modulations in the porcine endometrium, induced in vivo by a single subclinical dose of LPS from Salmonella Enteritidis. which did not produce clinical symptoms of toxicity. The RNA-seq methodology was applied to reveal 456 differentially expressed regions, including 375 genes, four long noncoding RNAs, and 77 other unclassified transcripts. Two independent methods confirmed 118 alternatively spliced genes that participate i.a., in the formation of the MHC-I complex and the adaptive immune response. Single nucleotide variant-calling algorithms supported the identification of 3730 allele-specific expression variants and 57 canonical A-to-I RNA editing sites. The results demonstrated that the differential expression of genes involved in inflammation, immune response, angiogenesis and endometrial development may be maintained for up to 7 days after exposure to LPS. RNA editing sites and long noncoding RNAs (lncRNAs) play an important role in transcriptional regulatory machinery in the porcine endometrium in response to LPS administration.
\end{abstract}

Keywords: LPS; RNA-seq; endometrium; alternative splicing; RNA editing; Sus scrofa

\section{Introduction}

The enteric pathogen Salmonella Enteritidis is causative agent of salmonellosis [1] and, in rare cases, extraintestinal disorders and septic shock [2]. This facultative intracellular pathogen colonizes specialized compartments in eukaryotic host cells. Salmonella enterica is able to survive in host cells 
by activating cellular stress response systems and highly evolved virulence factors [3]. The cell walls of Salmonella and other Gram-negative bacteria contain lipopolysaccharide (LPS) which binds with Toll-like receptors (TLRs) in the eukaryotic cells, promotes the transduction of inflammatory signals and activates the immune system during uterine infections [4]. About $80 \%$ of all genital tract infections are induced by E. coli [5]. Therefore, most research into LPS has been conducted with the involvement of E. coli, whereas Salmonella serotypes were far less frequently used [6]. Every year, about 3.4 million worldwide cases of extra-intestinal non-typhoidal Salmonellae (NTS) infections are observed [7]. Particularly, the bacteremia is mostly induced by NTS serotypes in sub-Saharan Africa populations [8]. Several known mechanisms participate in crossing the intestinal barrier by the Salmonella species [9]. Recent studies indicate that bacteria are transported by mononuclear cells and they also float as free microorganisms in the bloodstream [10]. Jeon and colleagues postulated that the same core bacterial genera are engaged in common biological networks in uterus and blood [11]. Following this lead, it is assumed that some pathogens may be transmitted to the uterus. Several medical case reports are describing Salmonella serotype infections linked with disorders of the reproductive tract and pregnancy complications in humans [12,13]. Moreover, the occurrence of Gram-negative bacteria within the uteroplacental unit increases the possibility of preterm labor or abnormal embryo preimplantation development [14].

The endometrium is the inner layer of the uterus which plays a role in implantation, placentation, and pregnancy maintenance [15]. Microbial uterine infections activate and attract innate immune cells which are indispensable for protecting the female reproductive tract [16]. High concentrations of bacterial endotoxins stimulate the expression and activation of pro-inflammatory cytokines in the endometrial tissues [17]. It has been demonstrated that the LPS-induced dysregulation of prostaglandin secretion is linked with the Toll-like receptor 4 (TLR4) signaling pathway, which explains the prolonged luteal phase in the bovine uterine disorders [18]. Dynamic changes in the uterine microenvironment during LPS administration were observed in many species [4,17-19], including pigs [20,21].

It has been found that LPS at a low dose $(5 \mu \mathrm{g} / \mathrm{kg} \mathrm{b.w})$ enhances fluctuations in gene and protein expressions in the porcine adrenal glands, gallbladder, brain and nervous system [22-25]. During pregnancy, the exposure to LPS at a high dose induces the intra-uterine fetal death [26]. However, even low doses of LPS can effectively induce inflammatory mediators such as PGE2, TNF- $\alpha$, IL-1 $\beta$, IL-6 and INFs [27,28]. There is evidence to suggest that low doses of LPS increase the expression of proinflammatory molecules without inducing septic shock, and this state is often called "endotoxin tolerance" [29]. After infection, most LPS molecules are cleared from the host, but $20 \%$ of LPS may still circulate in the bloodstream for a long time and interact with the innate immune system [30]. Most studies on pigs focused on LPS injected at moderate or high doses and no longer than $12 \mathrm{~h}$ after administration, precluding the possibility of discovering its long lasting effects on animal or human physiology [31].

The effect of bloodborne Salmonella LPS on the transcriptome of the porcine endometrium has not been studied to date. Research into genome-wide expression profiling has analyzed differentially expressed genes (DEGs), alternative splicing events, expression polymorphisms and expression targets to identify the links between various physiological or pathophysiological statuses and genetic backgrounds. Multilayered and deep genetic investigations of the host-pathogen interaction are a prelude and necessary step for proteomic and metabolomic approaches, that will bring us closer to the clinical implementations. The basic gene expression profiles and their changes are only a small part of the genetic overview of the experiments. Developing high-throughput sequencing methods has proven to be growing role of junk RNA and alternatively spliced transcripts.

The aim of this experiment was to describe in vivo genetic modifications in the endometrium of pigs administered a low single dose of LPS from Salmonella Enteritidis. No noticeable clinical symptoms of intoxication after 7 days of the LPS injection can hypothetically take place during the asymptomatic carrier state of Salmonella spp. A long-term contact with the pathogen, in particular with a bloody supply tissue/organ such as the uterus, may also lead to the host adaptive immune response. 
This study focused on a long-term impact of LPS on the porcine endometrial transcriptome induced by contact with the pathogen.

\section{Results}

\subsection{Mapping and Clustering of RNA-Seq Libraries}

Created RNA-seq libraries were sequenced in three biological replications for LPS-treated and control groups (Figure S1). Transcriptome-wide analysis of the effects of LPS administration on the endometrium was described on pipeline (Figure 1).

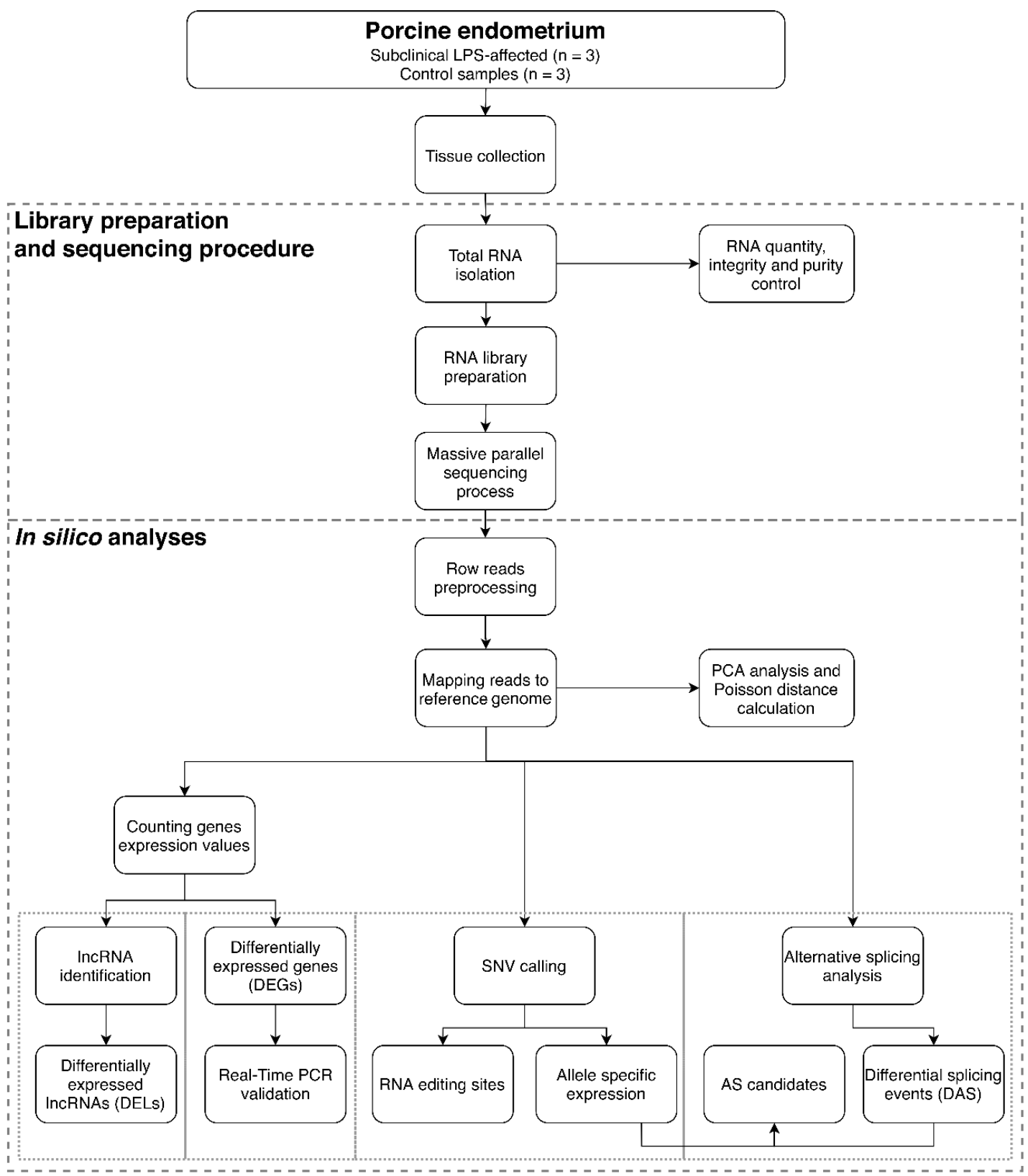

Figure 1. Flowchart of the RNA-seq wet-lab and in silico analyses. The main analytic pipeline contains: preprocessing quality control, mapping reads, biological replicates validation, differential genes and long noncoding RNAs (lncRNAs) expression analysis, alternative splicing events identification, allele-specific expression, RNA editing sites and real-time PCR validation. LPS-lipopolysaccharide; SNV—-single nucleotide variant; AS—alternative splicing; PCA—principal component analysis. 
HiSeq 4000 (Illumina) sequencer generated 282,664,081 raw paired-end reads (Table 1). Preprocessing quality control procedure survived 260,974,918 clean reads, and of them, 216,501,753 were uniquely mapped to the reference porcine genome (Sscrofa11.1.91). The mean percentage distribution of aligned reads to the genome was as follows: $36 \%$ to CDS regions, $24 \%$ to UTRs regions, $5 \%$ to introns and 35\% to intergenic locations (Table S1). We identified 21,054 transcriptionally active regions (TARs). in the porcine endometrium, that were expressed in at least half of the examined samples. The calculation of te Poisson distance (Figure 2A) and principal component analysis (PCA) (Figure 2B) revealed that the expression pattern of the samples clustered according to biological replicates within the LPS-treated $(\mathrm{n}=3)$ and non-treated $(\mathrm{n}=3)$ groups.

Table 1. Overview of the sequencing and mapping results for the six RNA-seq libraries. CTR 1, 2, 3 refers to the biological replicates of the control porcine endometrium; LPS 1, 2, 3 refers to the porcine endometrium after LPS administration; unique reads refer to the reads mapped to only one location of the porcine genome; multi-mapped reads refer to reads aligned to more than one locus on the reference genome; reads mapped with too many loci refer to the reads mapped more than 20 to multiple loci on the reference genome.

\begin{tabular}{ccccccc}
\hline SAMPLE & CTR1 & CTR2 & CTR3 & LPS1 & LPS2 & LPS3 \\
\hline Raw reads & $107,429,702$ & $89,680,918$ & $84,472,314$ & $97,318,676$ & $90,921,644$ & $95,504,908$ \\
Trimmed reads & $99,350,630$ & $82,942,056$ & $78,186,984$ & $89,746,640$ & $83,948,534$ & $87,774,992$ \\
Mapped reads & $97,654,932$ & $81,309,628$ & $76,784,982$ & $88,226,984$ & $82,560,754$ & $85,830,024$ \\
Uniquely mapped reads & $89,527,396$ & $60,499,072$ & $58,793,660$ & $80,185,286$ & $70,781,032$ & $73,217,060$ \\
Multi-mapped reads & $8,066,184$ & $20,785,528$ & $17,964,626$ & $7,990,104$ & $11,741,434$ & $12,567,688$ \\
Reads mapped with too many loci & 61,352 & 25,028 & 26,696 & 51,594 & 38,288 & 45,276 \\
\hline
\end{tabular}




\section{A}

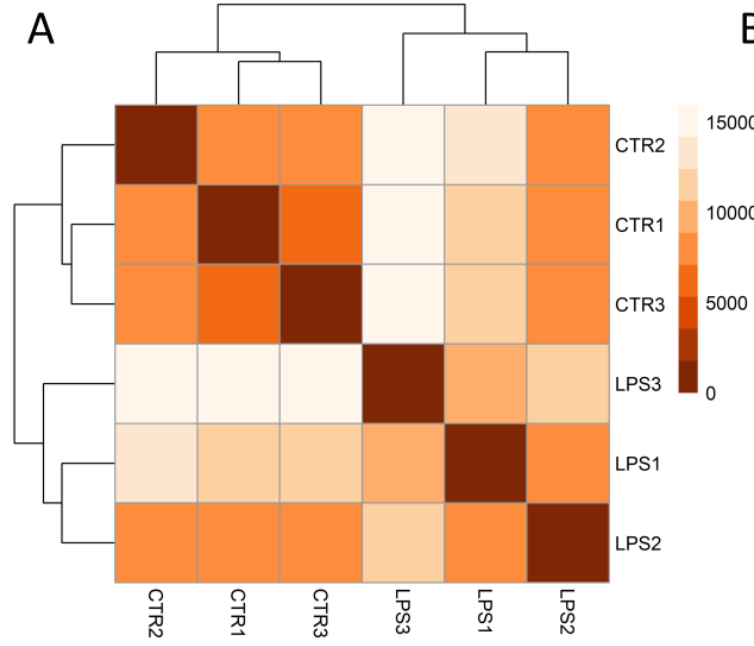

C

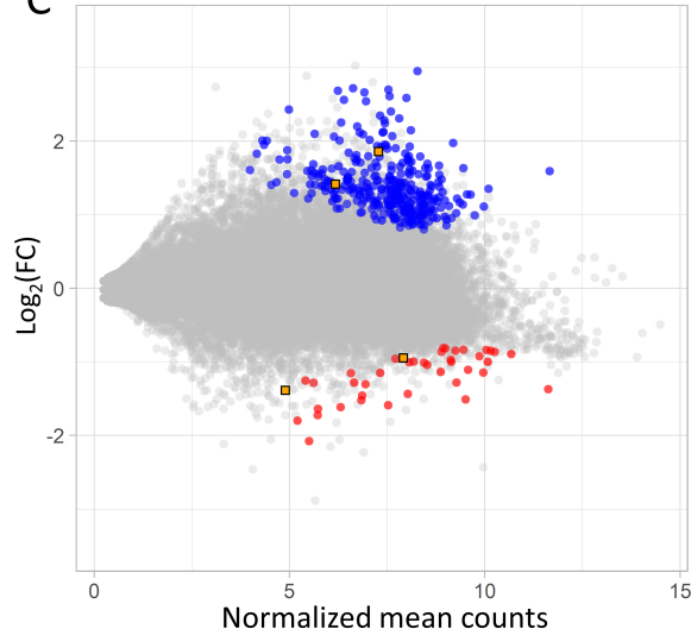

B

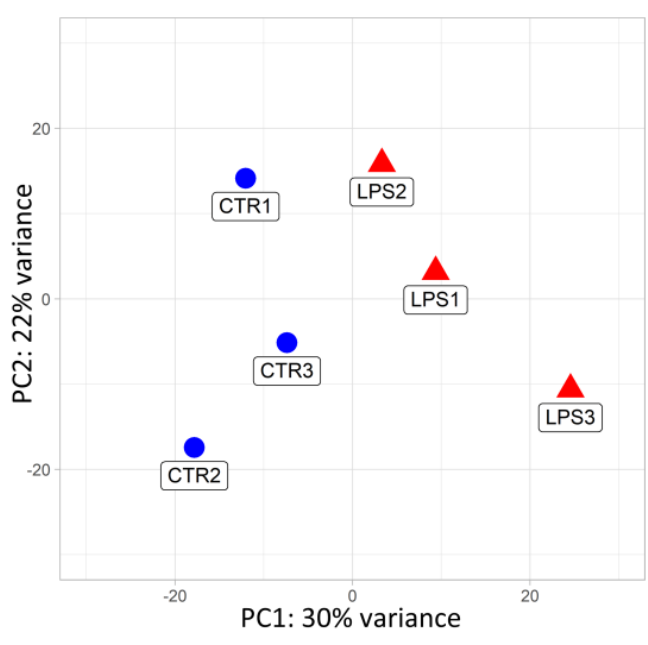

D

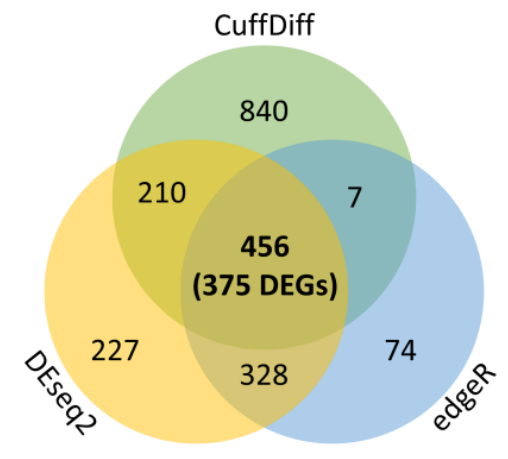

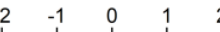

E

E

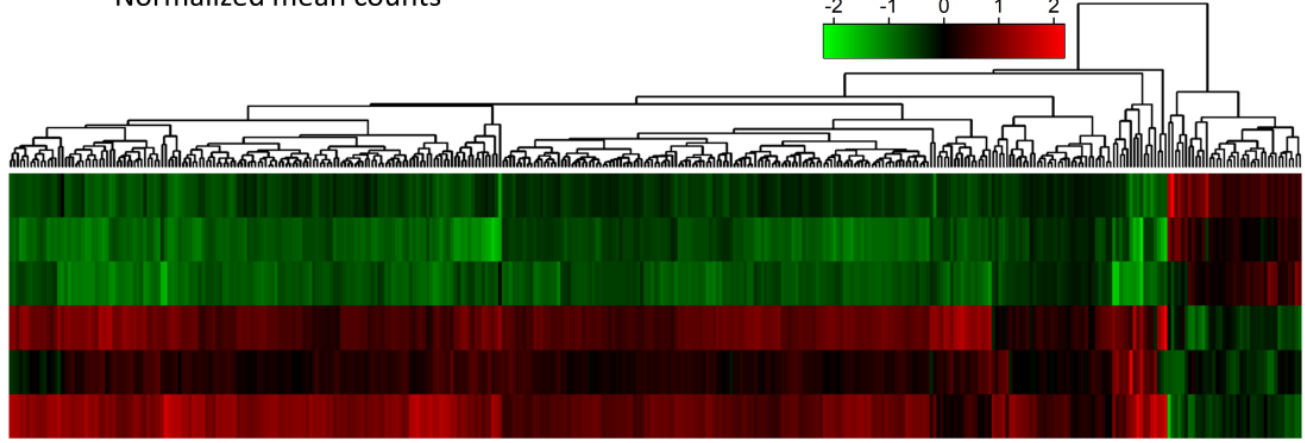

Figure 2. Transcriptome-wide RNA-seq analysis and expression profiles of the differentially expressed genes (DEGs) and lncRNAs (DELs) after LPS administration in endometrium. (A) The Poisson distance matrices of the transcriptomic profiles in the porcine endometrium treated by LPS. (B) Principal component analysis (PCA) of 6 RNA-seq libraries isolated from the endometrium ( $3 \times$ treated by low dose of LPS - red triangles; and $3 \times$ controls-blue circles); $X$ axis describes the principle component 1 and $Y$ axis depicts principle component 2 results; (C) MA plot presents the logarithmic scale of the fold changes in the $Y$ axis and the normalized expression count values in the $X$ axis. Blue dots represent upregulated DEGs, red dots describe downregulated DEGs and orange rectangles depict significant DELs. (D) Venn diagram of differentially expressed transcriptionally active regions (DE-TARs). Numbers in circles represent DE-TARs classified by DESeq2, Cufflinks and edgeR. Middle numbers include DE-TARs and DEGs intersected by those methods. (E) Heatmap of DEGs based on the the $\mathrm{Z}$ scores scale. Columns in heatmap represent DEGs; rows indicate individual RNA-seq libraries. 


\subsection{Differentially Expressed Genes (DEGs) and Functional Annotations}

Three methods, Cufflinks, DESeq2, and edgeR detected 1513; 1221 and 865 differentially expressed TARs (adjusted $p$-value $<0.05$ ), respectively, and 456 TARs were confirmed by all three methods (Figure 2D). The expression profiles of all transcripts were described by normalized counts values, logarithmic fold change $(\log 2 \mathrm{FC})$ and adjusted $p$-value in MA plot (Figure $2 \mathrm{C})$. Within the differentially expressed TARs, 375 DEGs showed statistically significant changes in the expression between the LPS-treated and the control samples (Table S2). The DEGs were visualized in a heatmap (Figure 2E). The 336 DEGs demonstrated overexpression and 39 were downregulated in the samples from the LPS group. The top five upregulated protein-coding genes were: EGFR $(\log F C=2.95)$, SIK1 $(\log F C=2.72)$, CEP250 $(\log F C=2.70)$, ARHGAP33 $(\log F C=2.68)$, CDC42BPG $(\operatorname{logFC}=2.66)$. Otherwise BTNL9 $(\log F C=-1.61)$, SIX1 $(\log F C=-1.64)$, TMEFF2 $(\log F C=-1.72)$, S100A9 $(\log F C=-1.80)$, and CCL23 $(\log F C=-2.08)$ genes, which showed the highest downregulation in LPS-treated samples (Table S2). Among all DEGs qualified to enrichment functional analysis, 313 were assigned to 24 biological processes (BP), 17 molecular functions (MF) and 26 cellular components (CC) gene ontology annotation terms (Figure 3, Table S3).

$$
\text { GO_aspect } \bigcirc \mathrm{BP} \bigcirc \mathrm{CC} \bigcirc \mathrm{MF}
$$

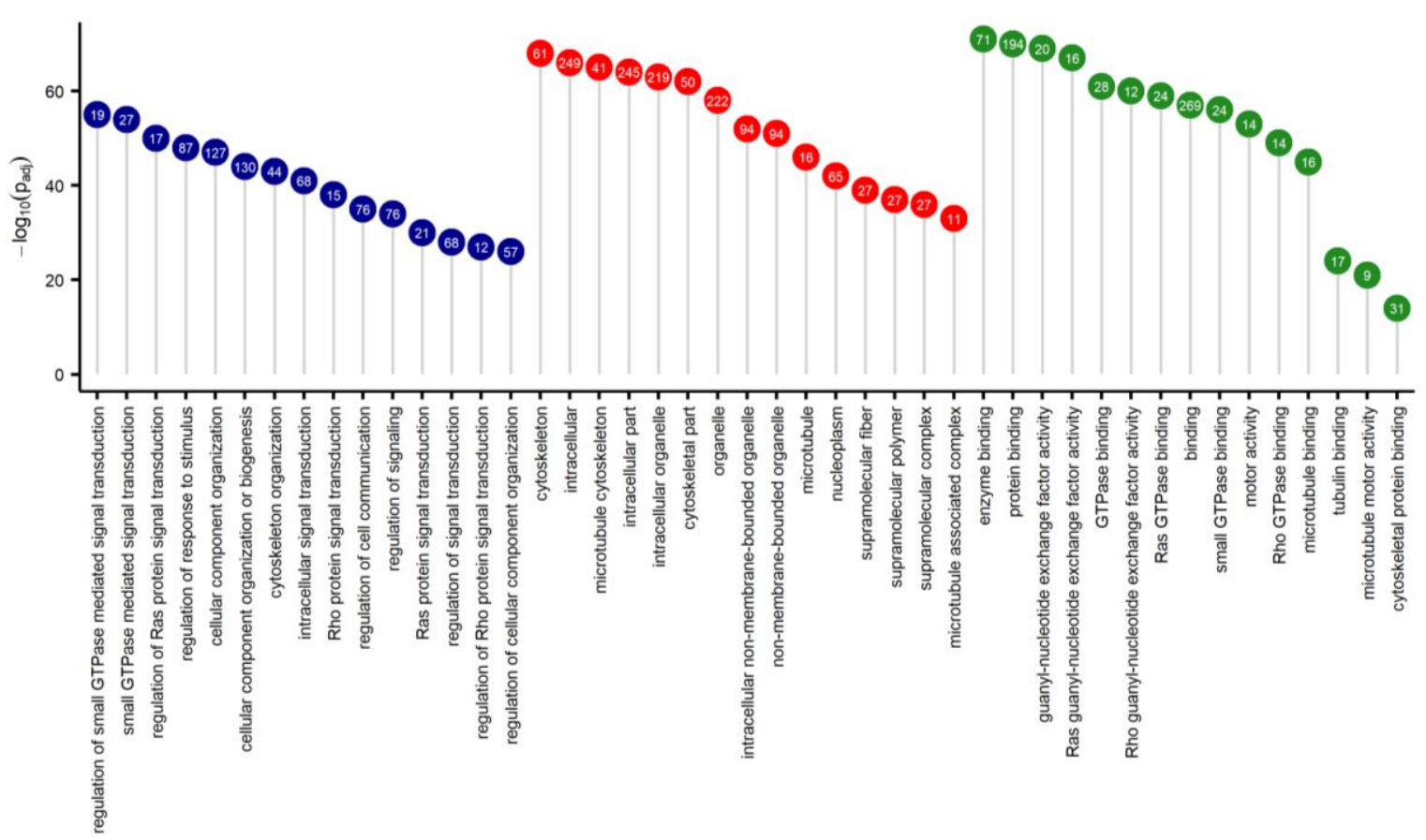

Figure 3. Lollipop chart of the top 15 Gene Ontology (GO) terms for each GO aspect (BP-biological process; CC—cellular components; MF-molecular function), scattered according to - $\log 10$ adjusted $p$-value. Numbers in circles refer to the number of DEGs annotated to the specific GO term.

Within the BP category, the most interesting DEGs were enriched to several subcategories: 'regulation of Ras protein signal transduction', 'regulation of response to stimulus', 'Rho protein signal transduction' and 'neurogenesis'. The MF aspect encompassed genes annotated to significant ontology terms, for example: 'Ras/Rho GTPase binding', 'enzyme binding' and 'microtubule motor activity'. Additionally, proteins coded by DEGs were cellular components of e.g., cytoskeleton, microtubule and collagen trimers. Metabolic pathways analysis revealed two significant Kyoto Encyclopaedia of Genes and Genomes (KEGG) items ('Thyroid hormone signaling pathway' and 'Notch signaling pathway'), that changed due to LPS injection. All six genes (ATXN1L, CREBBP, DLL1, P300, NCOR2, NOTCH1) assigned to the Notch signaling pathway were upregulated (Figure 4). 


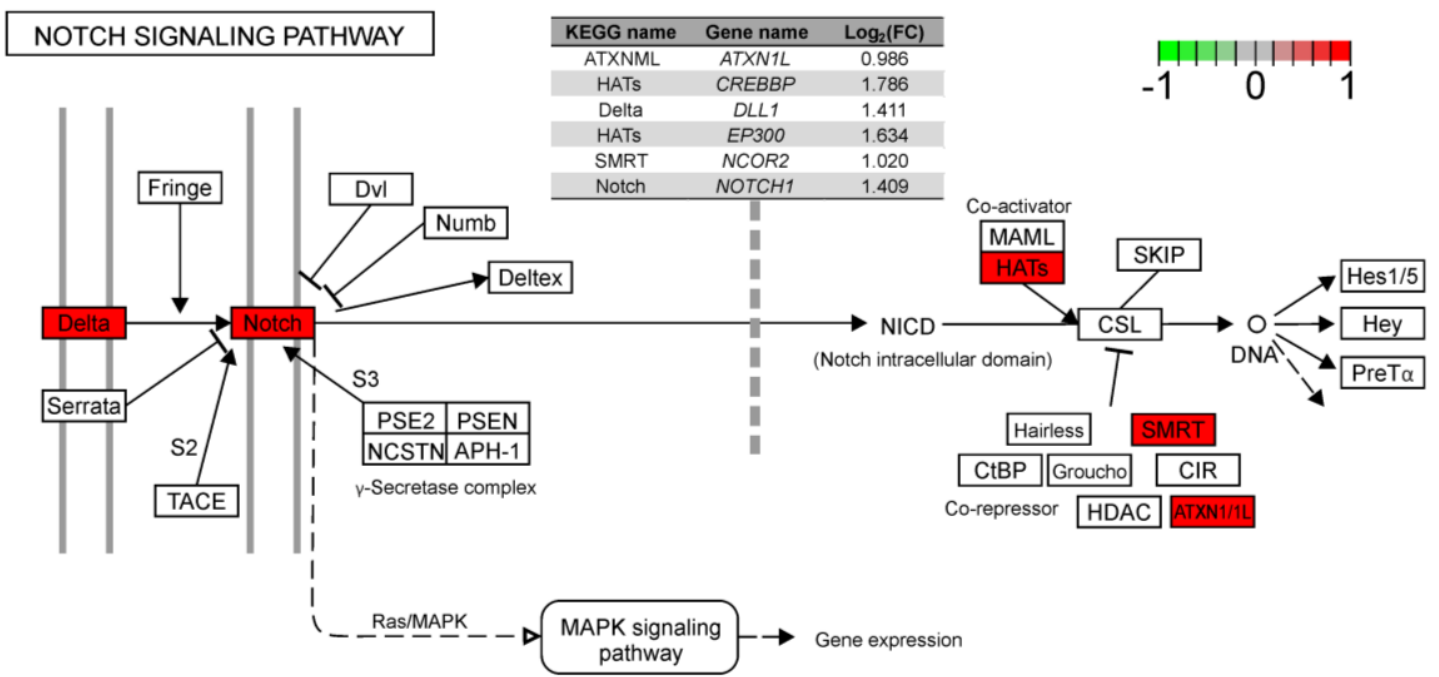

Figure 4. Enrichment Kyoto Encyclopaedia of Genes and Genomes (KEGG) analysis of DEGs engaged in the Notch signaling pathway.

Among the genes engaged in the TLR4 signaling pathway, only TRAF3 indicated significant upregulation in the samples from the experimental group.

The results revealed the dysregulation of the six crucial biomarkers involved in endometritis: SLC7A5, COL1A1, AXIN2 (upregulated); CFD, MGP, CCDC3 (downregulated). The other important DEGs were involved in the synthesis of fatty acids (FASN, $\operatorname{logFC}=1.66$ ), signal transduction pathways (CREBBP, $\log F C=1.79 ;$ p300, $\log F C=1.63)$, angiogenesis $(E G F R, \log F C=2.95 ;$ VEGFA, $\log F C=1.26)$ and defensins production (PLA2G4B, $\log F C=1.12 ;$ ALOX15, $\log F C=1.71)$.

\subsection{Long noncoding RNA (lncRNA) Identification and Cis/Trans-Connection with Protein-Coding Genes}

In the first filtration step, after removing protein-coding genes, sequences shorter than $200 \mathrm{bp}$ and one-exon transcripts from the annotated dataset, we detected 1802 potential lncRNA candidates expressed in the porcine endometrium. The obtained sequences were scanned for coding potential by four methods (CPAT, CPC2, FEELnc, Pfam) and 1072 unannotated transcripts were indicated as lncRNA biotype. Neither of the identified transcripts matched to small RNA models in the Rfam database. Identified novel lncRNA transcripts and 113 known lncRNAs were located in 773 non-coding regions. To examine the transcription regulatory machinery during LPS administration in the porcine endometrium, we retrieved two (MSTRG.3558, MSTRG.19846) upregulated and two (MSTRG.9270, MSTRG.15739) downregulated lncRNA loci (Table 2).

Table 2. Differentially expressed lncRNAs identified in the porcine endometrium after 7 days of subclinical LPS administration. MSTRG—cufflinks/stringtie identifiers on gene level; log2FC—log2 fold change.

\begin{tabular}{cccccccc}
\hline Gene_ID & Log $_{\mathbf{2}}$ (FC) & P-Adj & Chr/Contig & Start & End & Strand & ENSEMBL ID \\
\hline MSTRG.3558 & 1.42 & $2.44 \mathrm{E}-03$ & 12 & $47,554,682$ & $47,562,366$ & - & NA \\
MSTRG.9270 & -0.95 & $1.41 \mathrm{E}-02$ & 2 & $11,923,739$ & $11,924,922$ & + & NA \\
MSTRG.15739 & -1.38 & $4.80 \mathrm{E}-03$ & 6 & $88,799,040$ & $88,800,470$ & - & NA \\
MSTRG.19846 & 1.86 & $1.64 \mathrm{E}-06$ & AEMK02000682.1 & $1,430,615$ & $1,441,540$ & + & ENSSSCG00000035563 \\
\hline
\end{tabular}

Only upregulated differentially expressed lncRNAs (DELs) showed trans-interaction with 30 target genes, due to the similarity of expression profiles (absolute value of the Pearson correlation coefficient $>0.9$ ) (Table S4). Trans-interactions revealed 26 and 17 potentially regulatory target genes for MSTRG.3558 and MSTRG.19846, respectively. Only one gene (C1QA) was positively regulated by 
MSTRG.9270 lncRNA. The 155 genes were located in the vicinity ( $<2000 \mathrm{bp}$ ) of 152 lncRNA (Table S5). Neither of the cis-acting lncRNA were identified in DELs dataset.

\subsection{Differentially Alternative Splicing (AS) Events}

Two approaches (rMATS and SUPPA) permitted to detect 45,023 and 45,217 splicing events. Both methods also supported the identification of 4605 (rMATS) and 633 (SUPPA) differentially alternative splicing (DAS) events, as a result of the comparison of treated and control samples. However, the consensus of both methods confirmed 192 and 214 DAS events, according to the intersection of genomic localization, respectively, for rMATs and SUPPA (Table S6). All DAS events were assigned to 118 protein-coding genes. Among the detected DAS events, eight were classified as skipping exons (SE), 19 as alternative $5^{\prime}$ splice sites (A5SS), 25 as alternative $3^{\prime}$ splice sites (A3SS), nine as mutually exclusive exons (MXE), and 131 as retained introns (RI) according to rMATS classification. SUPPA grouped 214 DAS events to seven types: eight (SE), 11 (A5SS), 24 (A3SS), three (MXE), 129 (RI), 33 (alternative first-AF) and six (last exon-AL) (Figure 5A, Table S6).

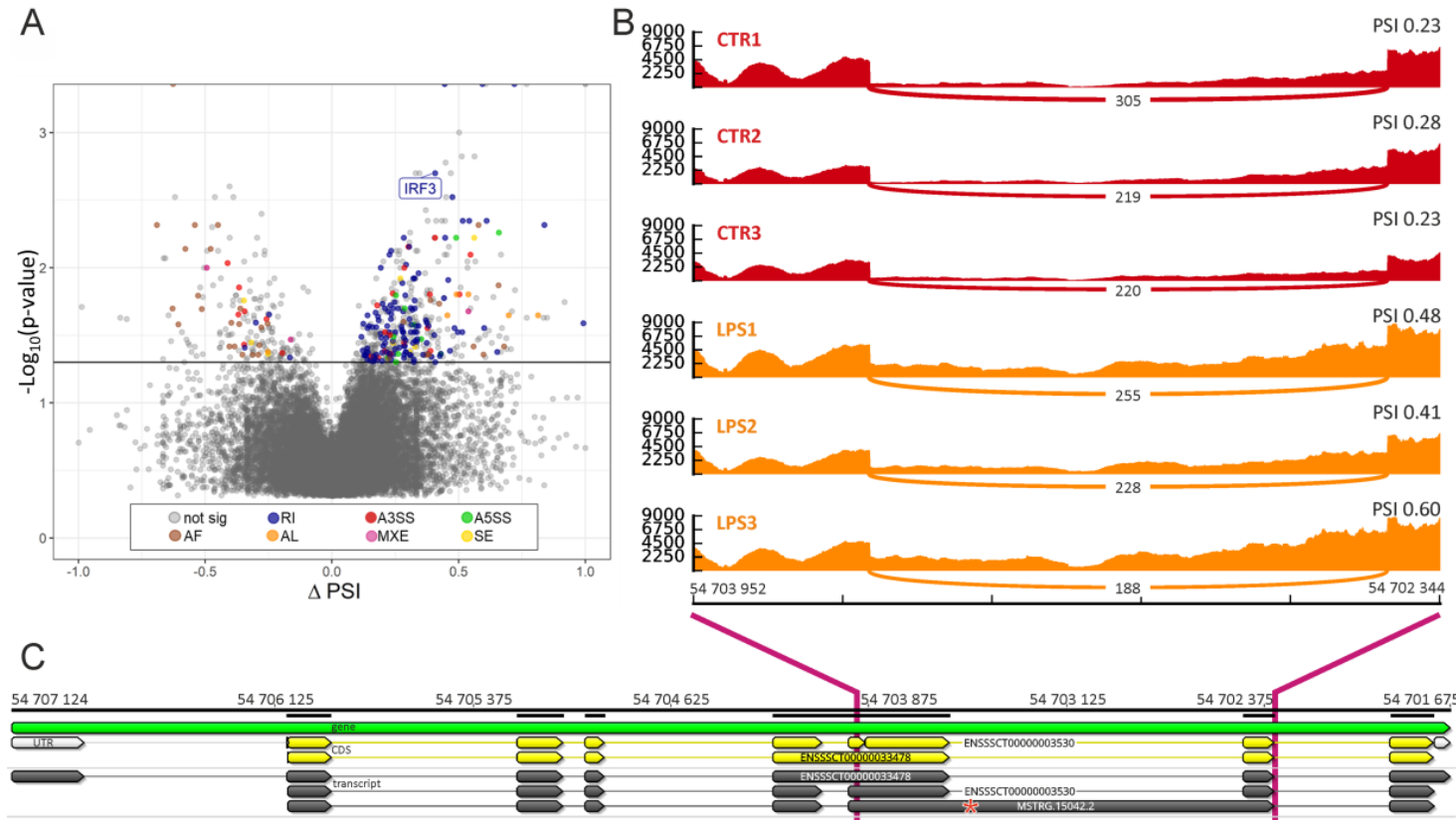

Figure 5. The distribution of differentially alternative splicing (DAS) events. (A) Volcano plot shows the difference in the percent splicing inclusion $(\triangle \mathrm{PSI})$ values in each alternative splicing $(\mathrm{AS})$ event ( $X$ axis) and the $Y$ axis depicts the logarithmic adjusted $p$-values. The horizontal line describes adjusted p-values cut-off (0.05). Colors of the dots indicate specific types of DAS: skipping exon (SE-yellow), alternative $5^{\prime}$ splice site (A5SS-green), alternative $3^{\prime}$ splice site (A3SS-red), mutually exclusive exons (MXE-pink), retained intron (RI-blue), alternative first (AF-brown), last exon (AL—orange), and not a significant event (grey). (B) Quantitative visualization (Sashimi plot) of the intron 5 (I5) retention within the IRF3 gene. Each track visualizes the splicing event (RI of I5) within the biological replicates for the control (red) and LPS-treated (orange) samples. Count values on curved lines describe the coverage within the splice junction. The left scale presents the coverage depth of IRF3 in the range of the AS region. PSI values are presented on the right side for each track. (C) Genomic coordinates of the DAS event within IRF3 located on chromosome 6. Yellow tracks show 2 known ENSEMBL coding regions (CDS) of the IRF3 gene. Grey tracks show 2 known and 1 novel transcripts of IRF3 identified in our study. Red star shows the position of the stop codon in the alternative spliced IRF3 mRNA (MSTRG.15042.2) after intron retention.

Most of the DAS events identified using both methods shared the same type of alternative splicing (AS). Discovered DAS genes were annotated to 11 Gene Ontology (GO) terms. The findings 
indicated that some genes (ENSSSCG00000001398, ENSSSCG00000001341, CD1D, FCGR1A, ADA) were enriched to 'antigen processing and presentation via MHC class $\mathrm{Ib}^{\prime}$ ' and 'positive regulation of adaptive immune response' (Table S7). Most of the important genes with identified DAS events, i.a., SIGIRR $(\triangle \mathrm{PSI}=0.291)$, HOXB7 $(\Delta \mathrm{PSI}=0.242)$, LIN7B $(\triangle \mathrm{PSI}=0.267)$ and IRF3 $(\Delta \mathrm{PSI}=0.408)$ (Figure $5 B, C$ ), revealed higher percentage splicing inclusion in LPS-treated samples. Otherwise, a higher percentage of exclusion was evaluated for CPT1B $(\triangle \mathrm{PSI}=-0.344)$, TGIF1 $(\triangle \mathrm{PSI}=-0.258)$ and SURF4 $(\triangle \mathrm{PSI}=-0.534)$. Furthermore, the three DEGs (CAPN15, ZSWIM8, AKAP17A) showed a higher percentage of the transcript with intron retention (RI) in the LPS-treated samples. Moreover, the CALU, CDK9, CIRBP, GPAA1, NAGK, NUDT14, STX18 and TOM harboured multiple types of DAS events within the junction sites, preferably noticed in the transcripts exposed to LPS.

\subsection{Allele-Specific Expression (ASE)}

Based on six RNA-seq libraries, 153,269 single nucleotide variants (SNVs) were called for the porcine endometrium transcriptome. Using standard GATK filters, 135,293 substitutions/sites survived the first step of the quality pipeline. Then, we obtained 86,972 polymorphic sites after removing the SNVs located in the range of bidirectional genes, simple sequence repeats, paralog regions and in the vicinity of splice junction sites. Finally, 53,472 SNVs possessed an alternative allele fraction in at least three RNA-seq libraries. After the filtering procedure, 3730 ASE candidates displayed a significant imbalance in allele expression (alternate allele frequency (AAF) $>0.1$; false discovery rate $($ FDR) < 0001) between the LPS-treated and the control samples (Figure 6; Table S8). According to the variant effect predictor (VEP) annotation, 865 ASE sites were depicted in downstream regions, 244 in upstream regions, 1065 on 3'UTR, 67 on 5'UTR, 283 within the intronic regions and 1074 on CDS sequences. Additionally, heterozygous ASEs were appraised as 2296 "heteroref", 1210 "heteroalt" and 224 "true" heterozygotes. ASE variants were identified in the range of 18 DAS genes and 55 DEGs (Figure 6).

\subsection{RNA Editing Prediction}

The 1422 polymorphic sites (with AAF < 0.7 in all samples and no annotation in dbSNP) were assigned to RNA canonical substitutions (A to I and $\mathrm{C}$ to $\mathrm{T}$ ). The fifty-three substitution sites were localized within Sus scrofa PRE-1 SINE regions, and these SNVs were qualified as RNA editing candidates. Additionally, twenty-two of them were confirmed in the pig editome DREP database. Adenosine to inosine ('A to I') RNA editing candidates were classified as 21 UTR, 14 downstream, 17 intronic and five upstream variants (Table 3). Finally, six of the RNA editing sites (located in the vicinity of SPPL2A, RSAD1, GFM1, ENSSSCG00000031589, TMEM161A, GNG3) also indicated significant $(\mathrm{FDR}<0.05)$ imbalance in allele fraction.

\subsection{Real-Time PCR Validation}

To validate the obtained RNA-seq results, six DEGs (BCAS4, MGMT, TRAF3, VEGFA, NOTCH1, IFI6) were selected for qRT-PCR. The qRT-PCR expression patterns of these DEGs agreed with the RNA-Seq results. qRT-PCR confirmed the veracity and accuracy of the high-throughput methods used in the present study (Figure 7). 


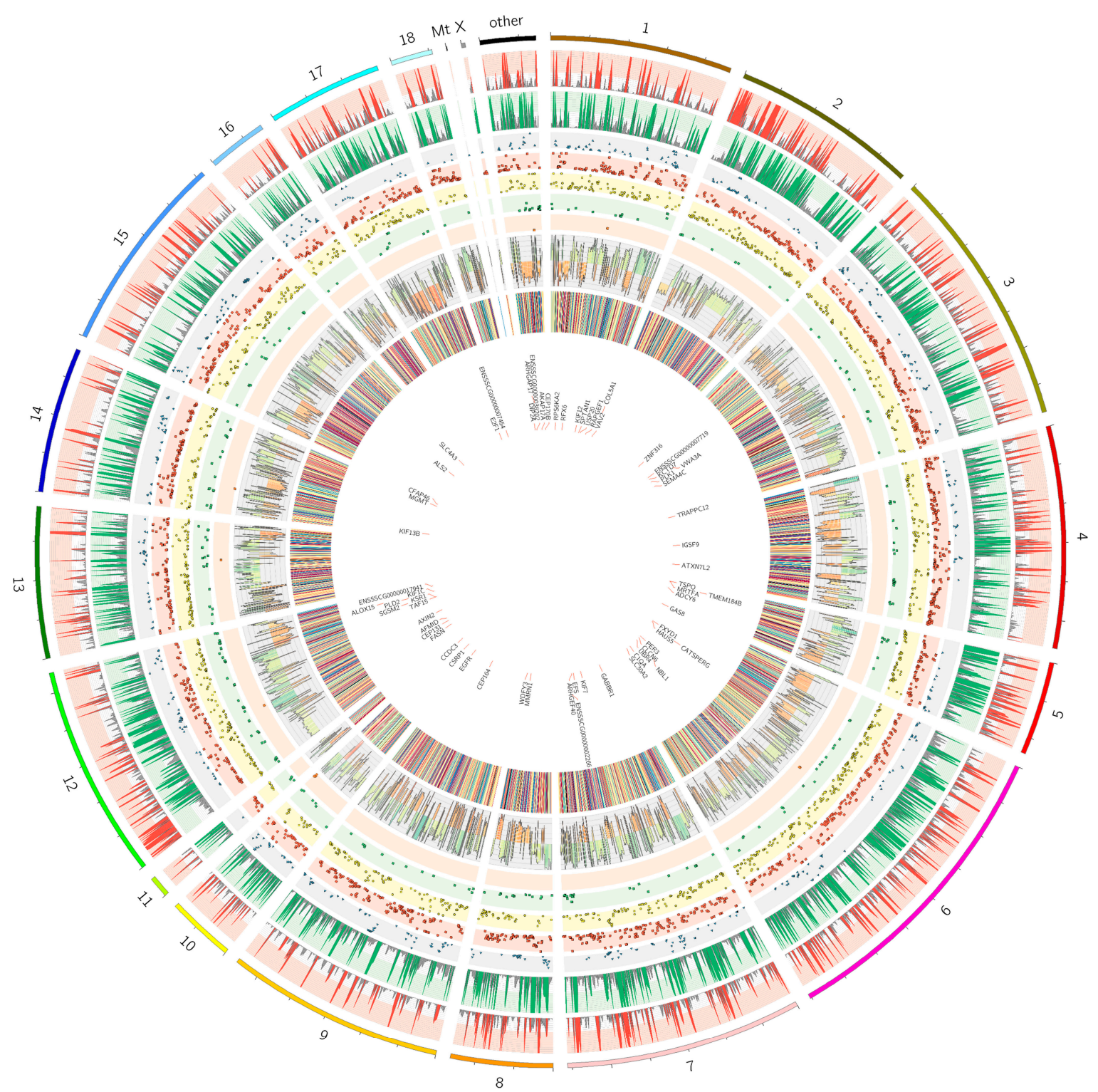

Figure 6. Visualization of the allele-specific expression (ASE) sites exposed to the low dose of LPS. The external circle represents the porcine chromosomes and scaffolds, where each chromosome length describes the number of ASEs. Two upper tracks depict the coverage of the reference (red histogram) and alternative variants (green histogram) in all the RNA-seq libraries. The next five middle scatter plots show the localization of ASE on intergenic (blue triangles), UTR (red squares), CDS (yellow dots), intron (green squares on green background) and ncRNA region (orange squares on orange background); vertical axis on each scatter plot shows the normalized FDR. The histogram visualizes a difference in the alternative allele fraction $(\triangle \mathrm{AAF}$ ) between the LPS-treated samples and the controls. In this track, green indicates a higher AAF in the controls and orange represents a higher AAF in the LPS samples. The tenth track (12-color barcode plot) presents an abundance of 12 types of nucleotide substitutions. The most inner track depicts the names of 55 DEGs with significant $\triangle \mathrm{AAF}$ in ASFE sites. 
Table 3. RNA editing sites identified in the porcine SINE regions expressed in the endometrium. Star ${ }^{*}$ ) in chromosome: site column indicates RNA editing site confirmed in DREP database. Variant annotations are described by SnpEff software.

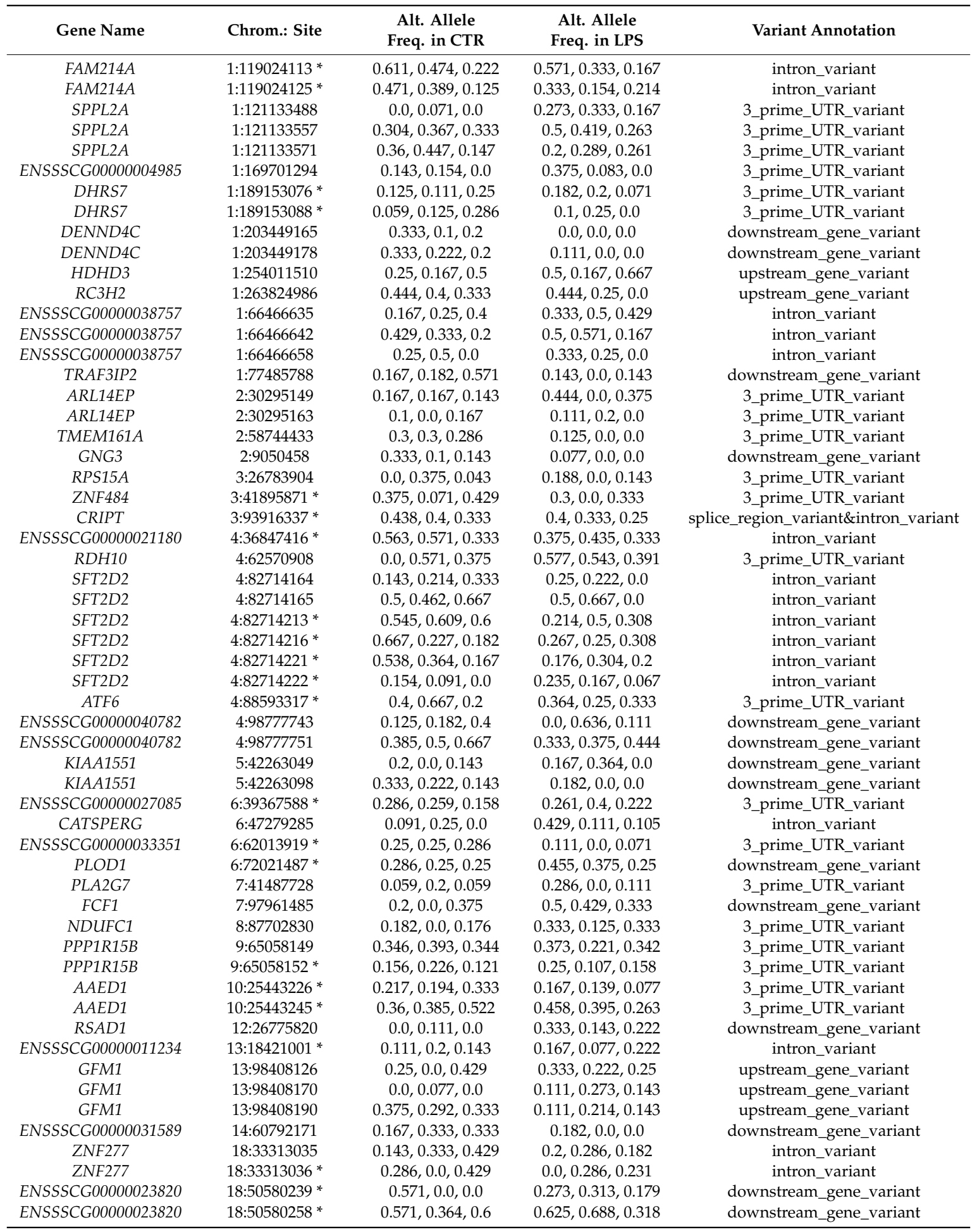



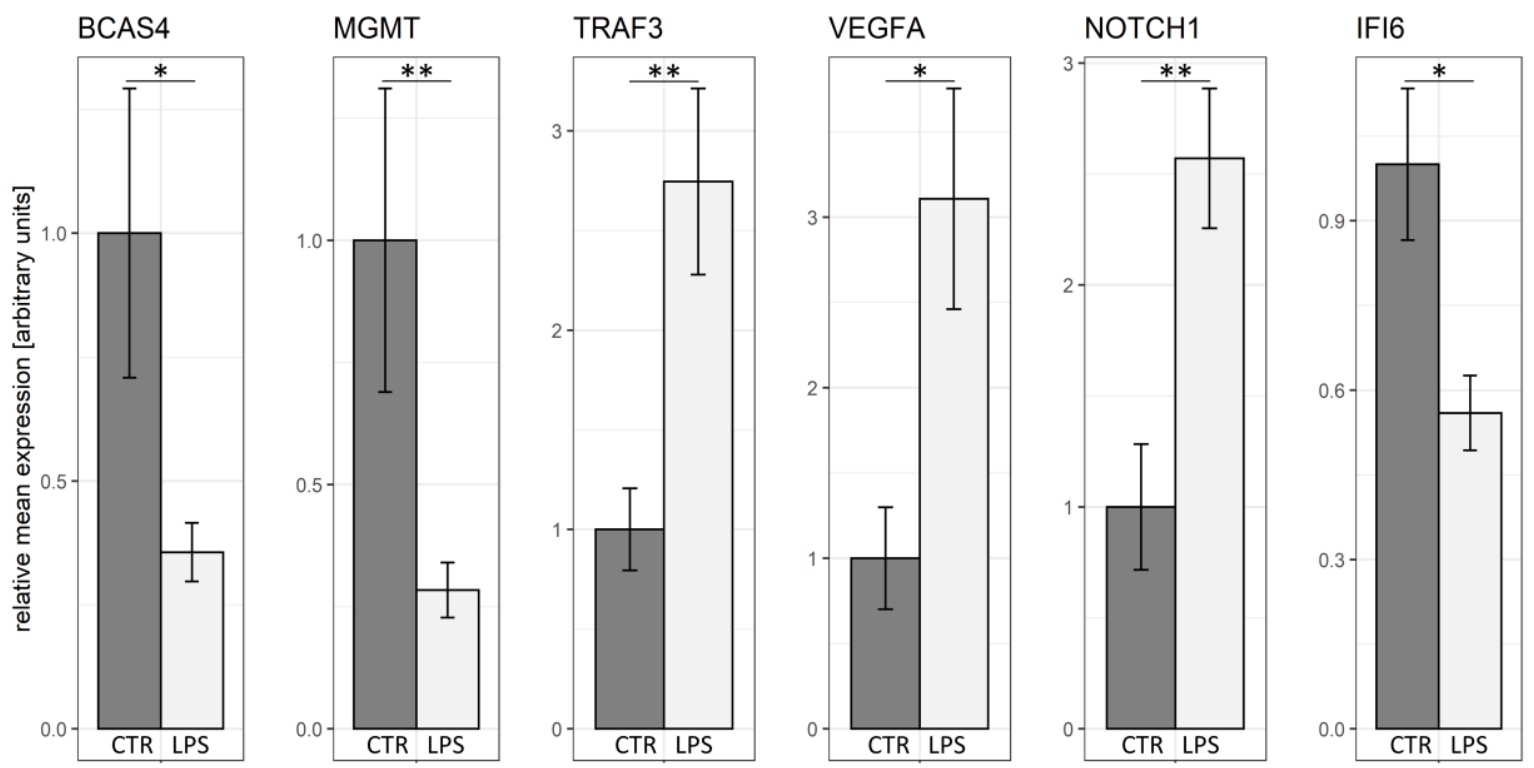

Figure 7. Real-time PCR validation of the RNA-seq results for the DEGs in the endometrial cells. Validation was performed for BCAS4, MGMT, TRAF3, VEGFA, NOTCH1 and IFI6 genes with reference genes (ACTB and PPIA). LPS—samples from the LPS-treated groups; CTR-samples from the control groups; ${ }^{*}$-value $<0.05 ; * *$-value $<0.01$.

\section{Discussion}

This study made the first ever attempt to describe transcriptomic changes in the porcine endometrium resulting from the exposure to a subclinical dose of Salmonella enterica LPS. A total of 375 protein-coding genes and four differentially expressed lncRNA loci were identified. The functional annotation of the analyzed genes demonstrated that DEGs (336 up-regulated and 39 down-regulated) were involved in, among others, the Notch signaling pathway, the Rho protein signal transduction and cytoskeleton formation. An analysis of alternative splicing events revealed 118 protein-coding genes with significant changes in exon and intron inclusion levels. The SNV calling approach revealed 3730 SNVs with differences in alternative allele fraction and 57 A-to-I canonical RNA editing candidates, which could play a regulatory role in response to a subclinical dose of LPS.

Lipopolysaccharide is produced by Gram-negative bacteria, and it plays a crucial role in the activation of pro-inflammatory cytokines which dysregulate the uterine microenvironment $[32,33]$. Neonatal exposure to LPS may have consequence in immune responses later in life [34]. Therefore, we may assume that LPS administration at a young age may be involved with uterine welfare in adulthood. This study proposes a model of a single low dose of $S$. enterica LPS injection to the uterus, without phenotypic symptoms of illness. The molecular pathways associated with the endometrial immune response to the presence of the pathogen in the bloodstream are still unknown. This study set out to investigate whether, and if so, which molecular mechanisms have been induced to suppress transcriptional responses leading to inflammation, after 7 days of infection. There is evidence to suggest that some pro-inflammatory cytokines may be engaged in normal uterine functioning during the menstrual/estrous cycle and early pregnancy $[35,36]$. However, gilts reach sexual maturity at around five/six months of age. Therefore, the confounding effect of the estrous cycle was disregarded, and only the symptoms triggered by LPS were investigated.

Innate immunity and mucosal defense systems are activated in the presence of bacteria in the female genital tract. Lipopolysaccharide is the main component of bacterial cell walls which induces the expression of TLR4 receptors, and consequently, activates the NF-kB transcription factor and stimulates the production of inflammatory cytokines [37]. Toll-like receptors mediate the production of cytokines and growth factors, as well as the proliferation of endometrial cells in response to LPS [38]. 
In the present study, the expression of most genes whose products are engaged in the TLR4 pathway was not significantly altered in the endometrium of pigs exposed to LPS. Only TRAF3 $(\log F C=1.81)$ was upregulated in LPS-treated animals. There is evidence to indicate that TRAF3 is an important signaling protein which participates in the inhibition of inflammatory cytokine production. TRAF3 has to be degraded to activate the MAPK signaling pathways and effector functions of the immune system [39]. Previous studies of bovine endometrial cells revealed that IRF3 depletion may inhibit the RIG-I signaling pathway [40]. The present study demonstrated that even the overexpression of TRAF3 did not affect the expression profile of IRF3 in the examined samples. However, alternative splicing analysis revealed higher inclusion levels of IRF3 intron 5 (I5) in LPS-treated samples, which could be attributed to the formation of more inactive IRF3 isoforms during translation. This study also revealed the presence of intron-retaining SIGIRR transcripts in the treated samples. Shorter mRNA products suppress the activation of SIGIRR protein, which could be linked with an immune tolerance to some microbial components after the silencing of the TLR signaling pathway [41]. The deactivation of JNK and p38 family members (members of MAPK kinase signaling cascades) may be a part of negative feedback involving DUSP8 [42]. The expression of DUSP8 was altered $(\operatorname{logFC}=1.44)$, which may mute MAPK and Toll-like signaling pathways.

The gene ontology enrichment analysis revealed the importance of the Ras/Rho protein signal transduction and Ras/Rho GTPase activation, after LPS administration in the porcine endometrium. Ras proteins activate all three types of MAPK in vascular smooth muscle cells, which generally increases cytoplasmic phospholipase A2 (cPLA2) expression [43] and/or cytokine production [44]. The activation of Rho is associated with the LPS/NF-kB signaling pathway. Virulence factors, including LPS, affect and interact with the actin cytoskeleton and RhoGTPases. The Rho signaling pathways also control trophoblast invasion in the endometrium [45]. This study also revealed the overexpression of RhoF $(\operatorname{logFC}=1.32)$ and two $C D C 42$ downstream effectors, $C D C 42 B P B(\operatorname{logFC}=1.27)$ and $C D C 42 B P G$ $(\log F C=2.66)$, which cooperate in cytoskeletal reorganization. $C D C 42$ and EGFR have been used as potential targets for angiogenesis and cancer therapies [46]. These findings suggest that the instability of the genes involved in Ras/Rho signaling pathways, in the endometrium of pre-pubertal gilts exposed to LPS, could lead to reproductive disorders.

Angiogenesis plays an important role in endometrial receptivity [47]. In this study, LPS treatment influenced several genes, including EGFR $(\log F C=2.95), V E G F A(\log F C=1.26)$ and NOTCH1 $(\operatorname{logFC}=1.41)$, whose products are involved in angiogenesis control. The activation of EGFR induces $V E G F$ overexpression in proangiogenic cells during the formation of new vessels [48]. Vascular endothelial growth factor (VEGF) signaling is strongly linked with NOTCH1 expression [49]. Endometrial tip cell migration and stalk cell proliferation are dependent on molecular cross-talk between VEGF and NOTCH1 [50]. A deficiency of both factors can induce arterial defects [51]. The involvement of the NOTCH signaling pathway in the overexpression of the NOTCH1 receptor and its ligand DLL1 plays a fundamental role in the development of endometrial arteries and maximizes reproductive success in mice [52]. The LPS injection also upregulated the ALOX15 gene $(\log F C=1.71)$ whose product controls cytokine generation [53], induces the proliferation of tumor cells and the dysregulation of angiogenesis. The adverse effects of $A L O X 15$ can be mitigated by the overexpression of $C P L A 2$. Cytoplasmic PLA2 releases arachidonic acid from the cell membrane which stimulates vein growth [54]. PLA2 also stimulates defensin production and plays a crucial role in the inhibition of bacterial enzymes [55]. This study revealed that ALOX15 and PLA2G4B $(\operatorname{logFC}=1.12)$ were upregulated in response to LPS, which suggests that LPS participates in both the disruptive and repair mechanisms of angiogenesis. These observations suggest that subclinical doses of LPS exert a more or less direct effect on angiogenesis in the porcine endometrium.

In many cases, a bacterial infection of the uterus can lead to clinical or subclinical endometritis [56,57]. This study confirmed differences in the expression profiles of six biomarkers in LPS-induced bovine endometritis: SLC7A5, COL1A1, AXIN2 (upregulated) and CFD, MGP, CCDC3 (downregulated) [57]. COL1A1 overexpression was also observed in the eutopic endometrium of 
infertile women with endometritis [58]. The presented experiment also revealed differences in the alternative splicing of TGIF1 induced by LPS administration. This gene was significantly dysregulated in cows with clinical and subclinical endometritis [57]. The discussed genes could play a key role in the molecular mechanisms underlying endometritis. It is worth noting that several transcripts (e.g., CD1D and ENSSSCG00000001398 encode MHC class I antigen 7, FCGR1A and ADA) enriched in the MHC class I protein complex, and the 'positive regulation of adaptive immune response' were significantly modified by alternative splicing. The overexpression of yjr MHC-I complex is linked with low fertility and endometritis [59]. Long-term endometritis may lead to impaired implantation [60] or cancerogenesis [61].

Research into human decidual cells has demonstrated that LPS influences the expression of genes engaged in lipid metabolism, including cholesterol and steroid biosynthesis [62]. Proprotein convertase subtilisin/kexin type 9 (product of PCSK9), the key regulator of serum cholesterol levels, inhibits LPS removal from the bloodstream [63]. The overexpression of PCSK9 reduces LPS clearance and may exacerbate tissue inflammation during sepsis [64]. Interestingly, a subclinical dose of LPS induced PCSK9 upregulation $(\log F C=1.60)$, which could have contributed to endometritis. A low LPS dose stimulated the fatty acid synthase gene $(F A S N$; $\log F C=1.66)$ which is linked with cholesterol synthesis and lipid raft formation [65]. The similarities in the FASN expression profiles in the adrenal glands of the same pigs [22] suggest that $F A S N$ is one of the fifteen genes that could act as a molecular signature of exposure to low LPS doses in pigs.

The administration of LPS also altered the expression of genes whose products are present in many hormonal signal transduction pathways. This study revealed the overexpression of genes encoding two coactivators, E1A Binding Protein P300 ( $p 300 ; \operatorname{logFC}=1.63$ ) and CREB Binding Protein (CREBBP; $\log \mathrm{FC}=1.79)$, as well as nuclear receptor corepressor $2(N C o R 2 ; \log F C=1.02)$. These factors are responsible for recruiting estrogen, progesterone and thyroid hormone receptors, and they play a critical role in embryonic development [66]. Subclinical doses of LPS can lead to dysfunctions of the signaling pathways and receptors.

The analysis of the interactions between trans- and cis-acting lncRNAs and mRNAs revealed three IncRNAs responsible for the positive regulation of protein-coding genes at independent loci and 212 lncRNAs located in the vicinity of target genes. A comprehensive analysis of lncRNA profiles revealed uncovered MSTRG.19846 and MSTRG.3558 IncRNAs that positively regulated DEGs (CREBBP and p300). MSTRG.3558 was also a trans-acting element of the TRIO gene which influences the Ras protein that participates in the signal transduction and cell growth [67]. The downregulation of the third IncRNA, MSTRG.9270, may inhibit the expression of C1QA, whose product is a component of the immune complement system [68]. Acting as cis-elements, lncRNAs may modulate the expression of closely related genes such as HMGB2 and $S E C 23 B$, which are implicated in nucleic acid-mediated TLR responses [69] and endometrial abnormalities [70], respectively. Long noncoding RNAs exhibit precise tissue-restricted expression, but in this study, we identified 112 expressed lncRNAs that are commonly encountered in both the endometrial and adrenal cortex tissues of pigs [22]. This study also confirmed the expression of 26 lncRNAs that had been identified in the porcine endometrium by Wang et al. [71]. This is the second study to demonstrate that subclinical doses of LPS induce changes in lncRNAs in porcine tissues, but it is the first ever study to examine the noncoding transcriptome of the endometrium under exposure to LPS. Our findings suggest that lncRNAs are important regulators of endometrial response to subclinical LPS doses, but DELs appear to play a key role in porcine adrenal glands [22].

There is still a broad range of unknown SNVs with unresolved functions and without specific annotation in the porcine genome. For this reason, there is a need to broaden and complement these ASE- and RNA editing catalogs by investigating every single SNV/SNP expressed in specific tissues essential e.g., for reproductive health and disorders. An analysis of alternate allele frequency (AAF) revealed that 3730 SNVs (FDR < 0.001) were involved in the endometrial response to a subclinical LPS dose. In the group of the identified ASE, 288 missense substitutions could lead to changes in 
protein sequence, folding and structure. Two nonsynonymous changes were observed in HMGB2 and PAF1 genes that are directly involved in the cellular response to LPS. Higher AAF of rs80832658 and rs326056210 in the LPS-treated samples could modulate the activation of both genes. There is evidence to indicate that the PAF protein family offers protection against LPS-induced endotoxemia [72]. A novel missense variant in AXIN2 and a variation (rs699379642) in PMS2, the biomarkers of uterine abnormality, have been identified in this study. The expression of PMS2 mutation has been found to increase the risk of endometrial cancer [73] and AXIN2 polymorphisms may activate the Wnt pathway associated with reproductive tract carcinomas [74].

In primates, RNA editing events are located in the Alu region $[75,76]$, but the pig genome is devoid of these repetitive regions [77]. After the multistep filtering procedure, we focused on 57 A-to-I editing sites located in PRE-1 SINE regions. The canonical A-to-I editing sites represent more than $90 \%$ of all mismatches in the repetitive regions such as the SINE region [77]. Our previous research [22] and the present study revealed that A-to-I editing sites occurred more frequently in the proximity of the 3'UTR of the SPPL2A gene in samples from the LPS-treated group. These findings imply that SPPL2A, which participates in the immune response, may be specially activated through RNA editing mechanisms, when Gram-negative bacteria infect different types of tissues. Comparing our results with the atlas of the RNA editome in Sus scrofa skeletal muscle [78], we confirmed 22 of 57 RNA editing sites expressed in the endometrial tissues. Significant AAF changes in 3'UTR TMEM161A and upstream from GFM1 could be linked with the potential mechanism of implantation failure [79] and intrauterine growth retardation [80], respectively. SNV-calling methods are valuable tools which expand our understanding of post-transcriptional modifications in the porcine genome.

It is worth mentioning that LPS may induce different biological effects dependently on the concentration of the endotoxin used. The limitation of our experimental model is the application of only one single low dose of LPS, and only one time point for the collection of tissue samples. The described above effects of LPS treatment may be due to the action of LPS molecules still circulating in the blood one week after administration, but it is also plausible that the LPS influence on uterine transcriptome partly disappeared after this time.

Deeper sequencing supports detailed analyses of the molecular mechanisms underlying essential physiological and pathological processes. Next-generation computational algorithms facilitate big biological data analyses. This study demonstrated that a subclinical dose of $S$. enterica LPS may induce significant transcriptomic changes that are involved in endometritis, immune response, angiogenesis and endometrial development. The gene ontology analysis of differentially spliced genes revealed the group of transcripts that play an important role in the adaptive immune response and antigen presentation via MHC-I. Our findings also indicate that tissue-specific transcriptomic regulatory mechanisms are activated in response to LPS administration. In the future, the impact of low-LPS doses on the endometrium should be explored with the use of single-cell RNA-seq methods to elucidate the expression patterns in different types of cells with established toxin tolerance.

\section{Materials and Methods}

\subsection{Ethics Statement and Collection of Samples}

The experiment was approved by the Local Ethical Committee for Animal Experimentation in Olsztyn, Poland, which is part of the National Ethics Commission for Animal Experimentation of the Polish Ministry of Science and Higher Education in Warsaw, Poland (Decision No. 73/2015 of 29 September 2015). The breeding and collection procedures were conducted in observance of all institutional guidelines applicable in the Republic of Poland according to the provisions of the Act of 15 January 2015 on Animal Welfare in Science and Education (Dz.U.2015.0.266). Six clinically healthy pigs (Pietrain $\times$ Duroc female) with a body weight of $16-18 \mathrm{~kg}$ were randomly divided into two groups: LPS (experimental) and control group. The immature pigs were used to avoid the effect of hormones associated with the estrus cycle on the uterine transcriptome. The control animals were injected 
with saline solution, while the pigs of the experimental group received LPS from Salmonella enterica serotype Enteritidis (catalogue No. L7770, Sigma Aldrich, Germany). Animals were intravenously injected (into the marginal ear vein) with LPS at a dose of $5 \mu \mathrm{g} / \mathrm{kg}$ b.w. (in $10 \mathrm{~mL}$ saline solution) for the treated group and with a $10 \mathrm{~mL}$ saline solution for control group. For seven days after the intravenous injection of LPS, the pigs did not exhibit any symptoms of illness. After seven days of LPS administration, the animals were anesthetized with propofol (Scanofol, NORBROOK, Northern Ireland) and euthanized with pentobarbital (Morbital, Biowet Puławy Sp. z o.o, Poland) [22]. The tissue sections of endometrium were collected immediately after euthanasia, washed in $0.9 \% \mathrm{NaCl}$, frozen in liquid nitrogen and stored at $-80^{\circ} \mathrm{C}$ until total RNA extraction. All information about the animal breeding, procedures of LPS injection and the health status of the animals belonging to the LPS and control groups were described previously $[25,81,82]$.

\subsection{Library Preparation and RNA-Seq Sequencing}

Global expression analysis was performed for the porcine endometrium of both the control $(n=3)$ and experimental $(n=3)$ groups. Briefly, the uteri of piglets were collected seven days after subclinical LPS administration. RNA extractions were described previously by Paukszto and coauthors [22]. To identify the expression profiles of the treated pigs, cDNA libraries were performed by TruSeq RNA Sample Prep Kit v2 with the unique pairs of adapters for each sample and RNA-seq was performed on the HiSeq 4000 Illumina platform (Illumina, San Diego, CA, USA). The raw data were submitted to the European Nucleotide Archive (ENA) under accession No. PRJEB37538.

\subsection{Transcriptome Expression Profiling}

Generated $2 \times 100$ bp paired-end reads were evaluated with FASTQC software version 0.11.7 [83]. Trimmomatic software v. 0.38 [84] was used for Illumina adaptors and poly(A) stretches removal (PHRED cutoff score $\leq 20$; calculated on both ends of reads and with $10 \mathrm{bp}$ frameshift). All reads were trimmed to equal length $(90 \mathrm{bp})$. After checking the quality, the paired-end reads were mapped to the pig reference genome with ENSEMBL/GENCODE annotation (Sus_scrofa.Sscrofa11.1.91) using the STAR mapper [85]. StringTie v. 1.3.3 [86] pipeline was used to annotate and estimate the expression of porcine genes and uncovered regulatory transcriptionally active regions (TARs). The integrity within the control and experimental RNA-seq libraries was verified by PoiClaClu and pheatmap Bioconductor packages of R software v.3.6.2 [87]. To identify the differentially expressed genes (DEGs), we applied the following statistical methods: Cufflinks [88], DESeq2 [89], edgeR [90]. The final consensus results constituted significant DEGs with known protein-coding annotation, confirmed by both statistical tests (adjusted $p$-value $<0.05$ ). Enrichment ontology and pathway analysis were performed with the use of gProfileR [91] based on gene ontology (GO) [92], and the Kyoto Encyclopaedia of Genes and Genomes (KEGG) [93] databases. DEGs were illustrated in an MA, a Volcano and a heatmap plots with gplots Bioconductor package and a custom script in R.

\subsection{Identification and Expression Profiling of Long Noncoding RNA (lncRNAs)}

The multi-stage workflow was implemented for lncRNA identification in the porcine endometrium. Firstly, protein-coding and low-expressed transcripts were excluded from the downstream analysis. Secondly, short (length $<200 \mathrm{bp}$ ) and one-exonic transcripts were also filtered out. Thirdly, the coding potential was estimated by the Coding-Potential Assessment Tool (CPAT) [94], Coding Potential Calculator (CPC2) [95], Flexible Extraction of LncRNAs (FEELnc) [96] and the Pfam 31.0 [97] databases. Survived transcripts without coding potential, i.a., CPC (score $<0$ ); FEELnc (coding potential $<0.558$ ); CPAT (cutoff $<0.43$ ) and Pfam (e-value $10^{-5}$ ), passed to further analyses. Moreover, transcripts with small noncoding RNAs Rfam [98] annotations were removed from the final predicted lncRNA dataset (novel/unannotated and annotated with lncRNA biotype). We investigated the expression profiles of the predicted lncRNAs within noncoding differential expressed TARs. Similarly to the analysis of DEGs, three binomial tests (Cufflinks, DESeq2, edgeR) with a cut-off adjusted $p$-value $<0.05$ were 
used to identify the differentially expressed lncRNAs (DELs). To uncover the relationship between lncRNAs and mRNAs, trans-and cis-regulatory elements were investigated. Trans lncRNA-mRNA connections were determined based on Pearson's correlation coefficient $(r>0.9$ or $r<-0.9)$ calculation of expression level using R software. We examined the cis-acting lncRNAs positioned from $2 \mathrm{kbp}$ distance of the gene using FEElnc and $\mathrm{R}$ softwares.

\subsection{Alternative Splicing Events}

To enrich the transcriptomic analysis, we predicted alternative splicing (AS) events by two methods: a super-fast pipeline for alternative splicing analysis (SUPPA v.2) [99] and replicate multivariate analysis of transcript splicing (rMATS v.3.2.5) [100]. Using equal length (90 bp) paired-end reads and Binary Alignment Map (BAM) files, we calculated the percent of splicing inclusion (PSI) for all splicing events. In the SUPPA method, we retrieved uniquely mapped reads from BAM files and remapped paired-end reads to the reference transcriptome using Salmon software [101]. Differential alternative splicing (DAS) events between the LPS-treated and control groups were statistically tested (FDR $<0.05$ ). Additionally, splicing sites with $\triangle \mathrm{PSI}>0.1$ were classified as significant. Alternative events were divided into five main types by rMATS software: alternative $5^{\prime}$ splice site (A5SS), alternative $3^{\prime}$ splice site (A3SS), mutually exclusive exons (MXE), retention intron (RI) and skipping exon (SE). SUPPA classified splicing events with two more types: alternative first (AL) and last exon (AL). Transcripts, with confirmed DAS events in both methods, were placed within a list of genes regulated by splicing. AS events were visualized in the maser package [102] and rmats2sashimiplot.py scripts [103].

\subsection{Allele-Specific Expression (ASE) Variants}

For the identification of single nucleotide variants (SNVs) changing the allele fraction between the LPS-treated and control samples, the multiple rMATS-DVR [104] and R Bioconductor pipeline were used. Firstly, all BAM files were recalibrated by Picard tool (http://broadinstitute.github.io/picard). Then, the variant calling analysis was performed with rMATS-DVR using golden-standard GATK tool [105]. Obtained data regarding the SNV calling were stored in a VCF file. Disturbed and low-quality SNVs were filtered out according to GATK standard parameters: total depth of base coverage < 10; RMSMappingQuality $<40$; QualitybyDepth $<2$; MappingQualityRankSum $<-12.5$; and ReadPosRankSum $<-8$. Subsequently, a removing procedure eliminated SNVs located in the vicinity of the exon-ntron junction ( $5 \mathrm{bp}$ range), within regions of bidirectional genes, within paralog regions (50 bp up- and downstream sequences) and simple sequence repeat (SSR) regions identified by GMATo tool [106]. Finally, the SNVs with an alternative allele fraction (AAF) $>0$ in at least half RNA-seq libraries and significant changes $(\triangle \mathrm{AAF}>0.1$ and FDR $<0.001)$ between the LPS-treated and control samples were qualified as ASE variants. An allelic imbalance ratio was confirmed by the chi-square goodness-of-fit test evaluating the frequencies of both nucleotides. All the identified ASEs were annotated by SnpEff [107] and a variant effect predictor (VEP) [108]. All the ASE candidates were plotted by Circos [109]. The ASEs were described by allele and reference fractions, chromosomal position, differences in allele fraction, FDR value, gene and single nucleotide polymorphism (SNP) annotations.

\subsection{RNA Editing Sites Prediction}

The filtration procedure (mentioned above in the ASE section) was extended by a few additional steps to find the RNA editing sites occurring in the porcine endometrium. SNVs with observed AAF in at least three samples were investigated in the RNA editing context. Only canonical A-to-I and C-to-U substitutions were separated for further analysis. SNVs with known SNP annotations (rs ID) in the Ensembl SNP database (version 91) were also removed. Assuming that $70 \%$ editing efficiency is unlikely, SNVs with AAF > 0.7 in any sample were filtered out. Chromosomal coordinates of the survived SNVs were intersected with Sus scrofa PRE-1 SINE regions using bedtools [110]. The final 
RNA editing A-to-I dataset was compared with the DREP database (one of few available porcine RNA editing databases [111].

\subsection{Quantitative Reverse Transcription PCR ( $q R T-P C R$ ) of DEGs}

Simultaneously with the sequencing procedure, RNA from the same six endometrial samples was isolated, as different technical replicates, and rewritten to cDNA. The 7300 Real-Time PCR System (Applied Biosystems, Foster City, CA, USA) was used to validate the expression profiles of DEGs. $A C T B$ and PPIA were selected as the reference genes. Primers for reference and target genes (BCAS4, MGMT, TRAF3, VEGFA, NOTCH1, IFI6) were projected using Primer Express Software 3 (Applied Biosystems). The qRT-PCR reaction conditions and all primers sequences for the reference and target genes were described in Table S9. PCR reaction mixture in a final volume of $20 \mathrm{uL}$ consisted of $12.5 \mathrm{uL}$ of the Sensitive RT HS-PCR Mix SYBR and $0.24 \mathrm{uL}$ Rox (A\&A Biotechnology, Poland), cDNA (20 ng), forward and reverse primers $200 \mathrm{nM}$ (NOTCH1, BCAS4, IFI6, VEGFA, TRAF3) or $500 \mathrm{nM}$ (MGMT) of each, and RNase-free water. Comparative cycle threshold method $(\triangle \triangle C T)$ [112] and geometric means of targets and reference gene expression levels were used for qRT-PCR validation. The results of qRT-PCR were statistically checked by the Student's $t$-test $(p<0.05)$ using Statistica software (Statsoft Inc., Tulsa, OK, USA).

Supplementary Materials: Supplementary Materials can be found at http://www.mdpi.com/1422-0067/21/12/4217/ s1. Figure S1. RNA-seq quality control evaluation of cDNA libraries according to $(a, b)$ concentration (ng/ $\mu \mathrm{L}, \mathrm{nM})$ and $(\mathrm{c}-\mathrm{h})$ size [bp]. Electropherograms were generated on the Agilent High Sensitivity D1000 ScreenTape assay. Table S1. Proportion of base pairs mapped to the porcine genome according to the gene structure. Distribution of bases mapped to the porcine reference genome and assigned to intergenic, intronic, UTR, and coding regions. Table S2. Differentially expressed protein-coding genes (DEGs) identified in the porcine endometrium after 7 days of subclinical LPS administration. Table S3. Gene Ontology enrichment classification of DEGs. $p$-value with cut-off < 0.05; BP-biological process; MF-molecular function; CC—cellular components. Table S4. Differentially expressed lncRNAs (DELs) positively correlated with DEGs. Pearson correlation coefficient (r) cut-off $>0.9$. Table S5. Intergenic lncRNAs (lincRNAs) connected with known transcriptionally active regions (TARs) in the distance shorter than $2 \mathrm{~kb}$. Table S6. Differentially alternative splicing (DAS) events discovered by SUPPA and rMATS tools. Seven and five alternative splicing event types show imbalance in the percent splicing inclusion (PSI) values investigated by SUPPA and rMATS, respectively. Table S7. DAS genes classified to the Gene Ontology terms. Table S8. Differences in alternative allele fraction $(\triangle \mathrm{AAF})$ for significant allele specific expression (ASE) sites identified in the porcine endometrium exposed to subclinical dose of LPS. Table S9. Sequences of primers and reaction conditions used in real-time PCR validation for DEGs and reference genes.

Author Contributions: Conceptualization, L.P., A.M. and T.K.; data curation, L.P. and J.P.J.; formal analysis, L.P., J.P.J. and M.K.; funding acquisition, N.S. and T.K.; investigation, L.P. and A.M.; methodology, L.P. and A.M.; project administration, A.M. and T.K.; resources, L.P., A.M., K.D. and M.K.; software, L.P. and J.P.J.; supervision, A.M., N.S. and T.K.; validation, K.D. and M.K.; visualization, L.P. and J.P.J.; writing-original draft, L.P., A.M., M.M. and T.K.; writing-review and editing, L.P., A.M., M.M. and N.S. All authors have read and agreed to the published version of the manuscript.

Funding: This study was supported by the University of Warmia and Mazury in Olsztyn (project No. 12.610.005-300).

Conflicts of Interest: The authors declare no conflict of interest. The funders had no role in the design of the study; in the collection, analyses, or interpretation of data; in the writing of the manuscript, or in the decision to publish the results.

Availability of Supporting Data: The datasets analyzed during the current study are available in the ENA database under accession number: PRJEB37538 (https://www.ebi.ac.uk/ena).

\section{Abbreviations}

$\begin{array}{ll}\text { lncRNAs } & \text { long non-coding RNAs } \\ \text { LPS } & \text { lipopolysaccharide } \\ \text { RNA-seq } & \text { RNA-sequencing } \\ \text { bp } & \text { base pair } \\ \text { NGS } & \text { next-generation sequencing } \\ \text { CPAT } & \text { Coding-Potential Assessment Tool } \\ \text { CPC } & \text { Coding Potential Calculator }\end{array}$




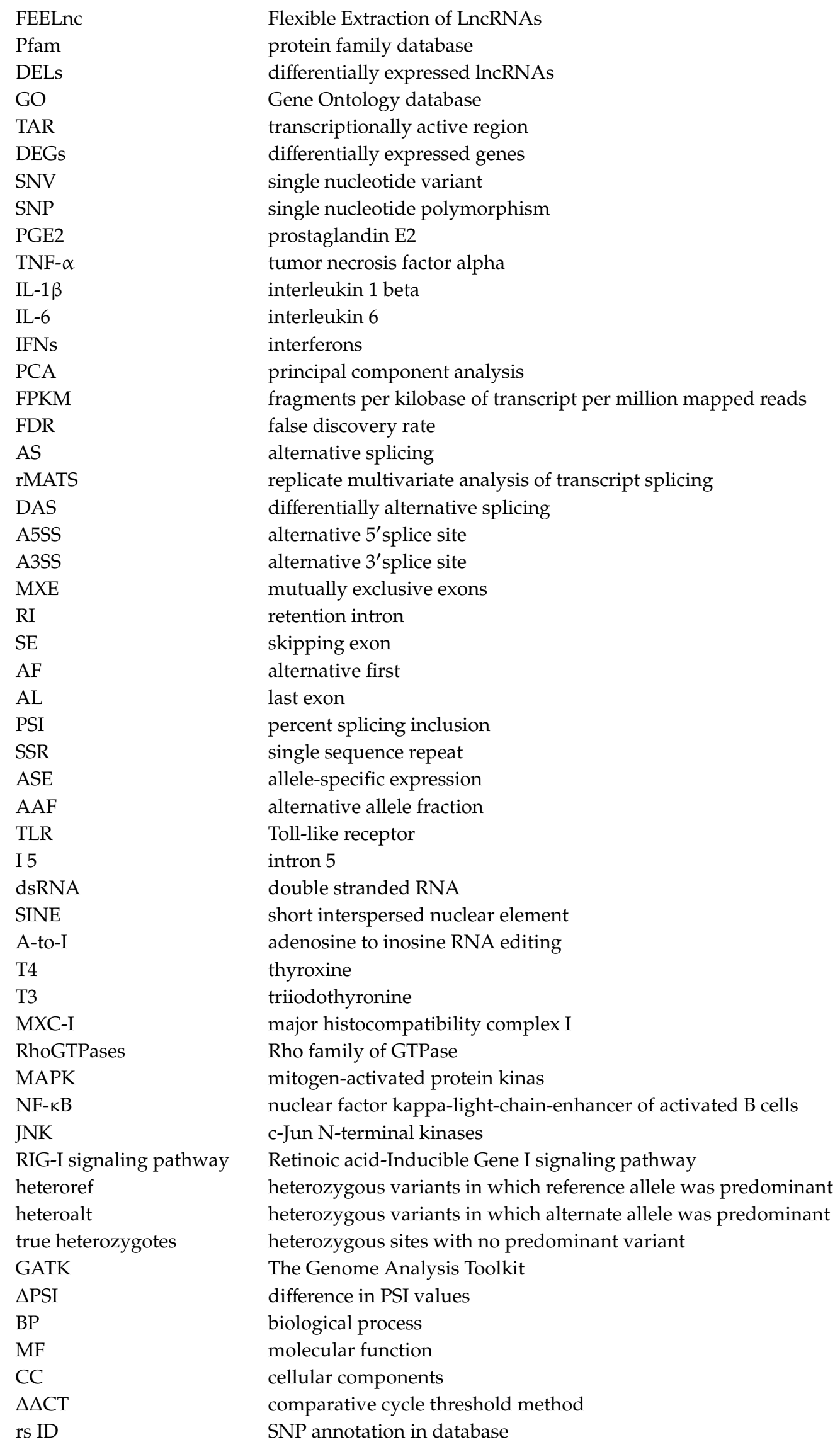




$\begin{array}{ll}\text { C-to-U } & \text { cytidine to uridine RNA editing } \\ \text { VEP } & \text { Variant Effect Predictor } \\ \text { VCF } & \text { variant calling format } \\ \mathrm{r} & \text { Pearson's correlation coefficient } \\ \text { KEGG } & \text { Kyoto Encyclopaedia of Genes and Genomes database } \\ \text { GO } & \text { Gene Ontology } \\ \text { ENA } & \text { European Nucleotide Archive }\end{array}$

\section{References}

1. Hohmann, E.L. Nontyphoidal Salmonellosis. Clin. Infect. Dis. 2001, 32, 263-269. [CrossRef]

2. Thompson Bastin, M.L.; Neville, N.R.; Parsons, R.E.; Flannery, A.H.; Tennant, S.J.; Johnson, C.A. An unusual case of Salmonella Enteritidis causing pneumonia, septic shock and multiple organ failure in an immunocompetent patient. IDCases 2016, 6, 85-89. [CrossRef] [PubMed]

3. Zenk, S.F.; Jantsch, J.; Hensel, M. Role of Salmonella enterica Lipopolysaccharide in Activation of Dendritic Cell Functions and Bacterial Containment. J. Immunol. 2009, 183, 2697-2707. [CrossRef]

4. Krikun, G.; Trezza, J.; Shaw, J.; Rahman, M.; Guller, S.; Abrahams, V.M.; Lockwood, C.J. Lipopolysaccharide Appears to Activate Human Endometrial Endothelial Cells Through TLR-4-Dependent and TLR-4-Independent Mechanisms. Am. J. Reprod. Immunol. 2012, 68, 233-237. [CrossRef]

5. Deb, K.; Chaturvedi, M.M.; Jaiswal, Y.K. A "minimum dose" of lipopolysaccharide required for implantation failure: Assessment of its effect on the maternal reproductive organs and interleukin- $1 \alpha$ expression in the mouse. Reproduction 2004, 128, 87-97. [CrossRef]

6. Mikołajczyk, A.; Złotkowska, D. Neuroimmunological Implications of Subclinical Lipopolysaccharide from Salmonella Enteritidis. Int. J. Mol. Sci. 2018, 19, 3274. [CrossRef]

7. Ao, T.T.; Feasey, N.A.; Gordon, M.A.; Keddy, K.H.; Angulo, F.J.; Crump, J.A. Global burden of invasive nontyphoidal salmonella disease, 2010. Emerg. Infect. Dis. 2015, 21, 941-949. [CrossRef]

8. Feasey, N.A.; Dougan, G.; Kingsley, R.A.; Heyderman, R.S.; Gordon, M.A. Invasive non-typhoidal salmonella disease: An emerging and neglected tropical disease in Africa. Lancet 2012, 379, 2489-2499. [CrossRef]

9. Jones, B.D.; Ghori, N.; Falkow, S. Salmonella typhlrnurium initiates murine infection by penetrating and destroying the specialized epithelial M cells of the peyer's patches. J. Exp. Med. 1994, 180, 15-23. [CrossRef] [PubMed]

10. Young, W.; Hine, B.C.; Wallace, O.A.M.; Callaghan, M.; Bibiloni, R. Transfer of intestinal bacterial components to mammary secretions in the cow. PeerJ 2015, 3. [CrossRef] [PubMed]

11. Jeon, S.J.; Cunha, F.; Vieira-Neto, A.; Bicalho, R.C.; Lima, S.; Bicalho, M.L.; Galvão, K.N. Blood as a route of transmission of uterine pathogens from the gut to the uterus in cows. Microbiome 2017, 5, 109. [CrossRef] [PubMed]

12. Rai, B.; Utekar, T.; Ray, R. Preterm delivery and neonatal meningitis due to transplacental acquisition of non-typhoidal Salmonella serovar montevideo. Case Rep. 2014, 2014. [CrossRef] [PubMed]

13. Singla, N. Salmonella Typhi Isolation in a Pregnant Woman: Determining the Importance. J. Clin. Diagn. Res. 2013, 7, 2100-2101. [CrossRef] [PubMed]

14. Rupasri, A.; Shivakumar, K.R.; Sreenath, B.R.; Seshagiri, P.B. Assessment of developmental retardation and abnormality of in vivo produced preimplantation embryos in rat. Indian J. Exp. Biol. 1995, 33, 911-916. [PubMed]

15. Wira, C.R.; Grant-Tschudy, K.S.; Crane-Godreau, M.A. Epithelial Cells in the Female Reproductive Tract: A Central Role as Sentinels of Immune Protection. Am. J. Reprod. Immunol. 2005, 53, 65-76. [CrossRef] [PubMed]

16. Sheldon, I.M.; Cronin, J.G.; Healey, G.D.; Gabler, C.; Heuwieser, W.; Streyl, D.; Bromfield, J.J.; Miyamoto, A.; Fergani, C.; Dobson, H. Innate immunity and inflammation of the bovine female reproductive tract in health and disease. Reproduction 2014, 148. [CrossRef]

17. Cronin, J.G.; Turner, M.L.; Goetze, L.; Bryant, C.E.; Sheldon, I.M. Toll-Like Receptor 4 and MYD88-Dependent Signaling Mechanisms of the Innate Immune System Are Essential for the Response to Lipopolysaccharide by Epithelial and Stromal Cells of the Bovine Endometrium1. Biol. Reprod. 2012, 86. [CrossRef] 
18. Sheldon, I.M.; Rycroft, A.N.; Dogan, B.; Craven, M.; Bromfield, J.J.; Chandler, A.; Roberts, M.H.; Price, S.B.; Gilbert, R.O.; Simpson, K.W. Specific Strains of Escherichia coli Are Pathogenic for the Endometrium of Cattle and Cause Pelvic Inflammatory Disease in Cattle and Mice. PLoS ONE 2010, 5, e9192. [CrossRef]

19. Jursza, E.; Szóstek, A.Z.; Kowalewski, M.P.; Boos, A.; Okuda, K.; Siemieniuch, M.J. LPS-challenged TNF $\alpha$ production, prostaglandin secretion, and TNF $\alpha$ /TNFRs expression in the endometrium of domestic cats in estrus or diestrus, and in cats with pyometra or receiving medroxyprogesterone acetate. Mediat. Inflamm. 2014, 2014. [CrossRef]

20. Jana, B.; Czarzasta, J. Effect of lipopolysaccharide and cytokines on synthesis and secretion of leukotrienes from endometrial epithelial cells of pigs. Anim. Reprod. Sci. 2016, 168, 116-125. [CrossRef]

21. Aisemberg, J.; Vercelli, C.A.; Bariani, M.V.; Billi, S.C.; Wolfson, M.L.; Franchi, A.M. Progesterone Is Essential for Protecting against LPS-Induced Pregnancy Loss. LIF as a Potential Mediator of the Anti-inflammatory Effect of Progesterone. PLoS ONE 2013, 8, e56161. [CrossRef] [PubMed]

22. Paukszto, L.; Mikolajczyk, A.; Szeszko, K.; Smolinska, N.; Jastrzebski, J.P.; Kaminski, T. Transcription analysis of the response of the porcine adrenal cortex to a single subclinical dose of lipopolysaccharide from Salmonella Enteritidis. Int. J. Biol. Macromol. 2019. [CrossRef] [PubMed]

23. Makowska, K.; Mikolajczyk, A.; Calka, J.; Gonkowski, S. Neurochemical characterization of nerve fibers in the porcine gallbladder wall under physiological conditions and after the administration of Salmonella enteritidis lipopolysaccharides (LPS). Toxicol. Res. Camb 2018, 7, 73-83. [CrossRef] [PubMed]

24. Mikołajczyk, A.; Kozłowska, A.; Gonkowski, S. Distribution and Neurochemistry of the Porcine Ileocaecal Valve Projecting Sensory Neurons in the Dorsal Root Ganglia and the Influence of Lipopolysaccharide from Different Serotypes of Salmonella spp. on the Chemical Coding of DRG Neurons in the Cell Cul. Int. J. Mol. Sci. 2018, 19, 2551. [CrossRef]

25. Mikołajczyk, A.; Złotkowska, D. Subclinical Lipopolysaccharide from Salmonella Enteritidis Induces Dysregulation of Bioactive Substances from Selected Brain Sections and Glands of Neuroendocrine Axes. Toxins Basel. 2019, 11, 91. [CrossRef]

26. Xu, D.-X.; Wang, H.; Zhao, L.; Ning, H.; Chen, Y.-H.; Zhang, C. Effects of low-dose lipopolysaccharide (LPS) pretreatment on LPS-induced intra-uterine fetal death and preterm labor. Toxicology 2007, 234, 167-175. [CrossRef]

27. Webel, D.M.; Finck, B.N.; Baker, D.H.; Johnson, R.W. Time course of increased plasma cytokines, cortisol, and urea nitrogen in pigs following intraperitoneal injection of lipopolysaccharide. J. Anim. Sci. 1997, 75, 1514-1520. [CrossRef]

28. Chae, B.S. Pretreatment of low-dose and super-low-dose LPS on the production of in vitro LPS-induced inflammatory mediators. Toxicol. Res. 2018. [CrossRef]

29. Biswas, S.K.; Lopez-Collazo, E. Endotoxin tolerance: New mechanisms, molecules and clinical significance. Trends Immunol. 2009, 30, 475-487. [CrossRef] [PubMed]

30. Correa, W.; Brandenburg, K.; Zähringer, U.; Ravuri, K.; Khan, T.; von Wintzingerode, F. Biophysical Analysis of Lipopolysaccharide Formulations for an Understanding of the Low Endotoxin Recovery (LER) Phenomenon. Int. J. Mol. Sci. 2017, 18, 2737. [CrossRef]

31. Nordgreen, J.; Munsterhjelm, C.; Aae, F.; Popova, A.; Boysen, P.; Ranheim, B.; Heinonen, M.; Raszplewicz, J.; Piepponen, P.; Lervik, A.; et al. The effect of lipopolysaccharide (LPS) on inflammatory markers in blood and brain and on behavior in individually-housed pigs. Physiol. Behav. 2018, 195, 98-111. [CrossRef] [PubMed]

32. Williams, E.J.; Fischer, D.P.; Noakes, D.E.; England, G.C.W.; Rycroft, A.; Dobson, H.; Sheldon, I.M. The relationship between uterine pathogen growth density and ovarian function in the postpartum dairy cow. Theriogenology 2007, 68, 549. [CrossRef] [PubMed]

33. Herath, S.; Lilly, S.T.; Fischer, D.P.; Williams, E.J.; Dobson, H.; Bryant, C.E.; Sheldon, I.M. Bacterial lipopolysaccharide induces an endocrine switch from prostaglandin F2alpha to prostaglandin E2 in bovine endometrium. Endocrinology 2009, 150, 1912-1920. [CrossRef] [PubMed]

34. Walker, A.K.; Nakamura, T.; Hodgson, D.M. Neonatal lipopolysaccharide exposure alters central cytokine responses to stress in adulthood in Wistar rats. Stress 2010, 13, 506-515. [CrossRef] [PubMed]

35. Koh, Y.Q.; Mitchell, M.D.; Almughlliq, F.B.; Vaswani, K.; Peiris, H.N. Regulation of inflammatory mediator expression in bovine endometrial cells: Effects of lipopolysaccharide, interleukin 1 beta, and tumor necrosis factor alpha. Physiol. Rep. 2018, 6, e13676. [CrossRef] 
36. Oliveira, L.J.; Mansouri-Attia, N.; Mansourri-Attia, N.; Fahey, A.G.; Browne, J.; Forde, N.; Roche, J.F.; Lonergan, P.; Fair, T. Characterization of the Th profile of the bovine endometrium during the oestrous cycle and early pregnancy. PLoS ONE 2013, 8, e75571. [CrossRef]

37. Ibrahim, S.; Szóstek-Mioduchowska, A.; Skarzynski, D. Expression profiling of selected miRNAs in equine endometrium in response to LPS challenge in vitro: A new understanding of the inflammatory immune response. Vet. Immunol. Immunopathol. 2019, 209, 37-44. [CrossRef]

38. Guo, J.; Chen, L.; Luo, N.; Li, C.; Chen, R.; Qu, X.; Liu, M.; Kang, L.; Cheng, Z. LPS/TLR4-mediated stromal cells acquire an invasive phenotype and are implicated in the pathogenesis of adenomyosis. Sci. Rep. 2016, 6, 21416. [CrossRef]

39. Häcker, H.; Redecke, V.; Blagoev, B.; Kratchmarova, I.; Hsu, L.-C.; Wang, G.G.; Kamps, M.P.; Raz, E.; Wagner, H.; Häcker, G.; et al. Specificity in Toll-like receptor signalling through distinct effector functions of TRAF3 and TRAF6. Nature 2006, 439, 204-207. [CrossRef]

40. Carneiro, L.C.; Bedford, C.; Jacca, S.; Rosamilia, A.; de Lima, V.F.; Donofrio, G.; Sheldon, I.M.; Cronin, J.G. Coordinated Role of Toll-Like Receptor-3 and Retinoic Acid-Inducible Gene-I in the Innate Response of Bovine Endometrial Cells to Virus. Front. Immunol. 2017, 8, 996. [CrossRef]

41. Li, D.; Zhang, X.; Chen, B. SIGIRR participates in negative regulation of LPS response and tolerance in human bladder epithelial cells. BMC Immunol. 2015, 16, 73. [CrossRef] [PubMed]

42. Chen, H.F.; Chuang, H.C.; Tan, T.H. Regulation of dual-specificity phosphatase (Dusp) ubiquitination and protein stability. Int. J. Mol. Sci. 2019, 20, 2668. [CrossRef] [PubMed]

43. Li, X.; Van Putten, V.; Zarinetchi, F.; Nicks, M.E.; Thaler, S.; Heasley, L.E.; Nemenoff, R.A. Suppression of smooth-muscle $\alpha$-actin expression by platelet-derived growth factor in vascular smooth-muscle cells involves Ras and cytosolic phospholipase A2. Biochem. J. 1997, 327, 709-716. [CrossRef] [PubMed]

44. Van Putten, V.; Refaat, Z.; Dessev, C.; Blaine, S.; Wick, M.; Butterfield, L.; Han, S.Y.; Heasley, L.E.; Nemenoff, R.A. Induction of cytosolic phospholipase A2 by oncogenic Ras is mediated through the JNK and ERK pathways in rat epithelial cells. J. Biol. Chem. 2001, 276, 1226-1232. [CrossRef]

45. Grewal, S.; Carver, J.; Ridley, A.J.; Mardon, H.J. Human Endometrial Stromal Cell Rho GTPases Have Opposing Roles in Regulating Focal Adhesion Turnover and Embryo Invasion In Vitro. Biol. Reprod. 2010, 83, 75. [CrossRef]

46. Maldonado, M.D.M.; Dharmawardhane, S. Targeting Rac and Cdc42 GTPases in Cancer. Cancer Res. 2018, 78, 3101-3111. [CrossRef]

47. Rashidi, B.; Malekzadeh, M. Evaluation of Endometrial Angiogenesis in Mice Uterus Before Implantation in Natural Cycles Followed by Use of Human Menopausal Gonadotropin-Human Chorionic Gonadotropin Drugs and Epigallocatechin Gallate. Adv. Biomed. Res. 2017, 6, 138. [CrossRef]

48. Tabernero, J. The role of VEGF and EGFR inhibition: Implications for combining anti-VEGF and anti-EGFR agents. Mol. Cancer Res. 2007, 5, 203-220. [CrossRef]

49. Cobellis, L.; Caprio, F.; Trabucco, E.; Mastrogiacomo, A.; Coppola, G.; Manente, L.; Colacurci, N.; De Falco, M.; De Luca, A. The pattern of expression of Notch protein members in normal and pathological endometrium. J. Anat. 2008, 213, 464-472. [CrossRef]

50. Blanco, R.; Gerhardt, H. VEGF and Notch in tip and stalk cell selection. Cold Spring Harb. Perspect. Med. 2013, 3, a006569. [CrossRef]

51. Tsao, P.-N.; Wei, S.-C.; Huang, M.-T.; Lee, M.-C.; Chou, H.-C.; Chen, C.-Y.; Hsieh, W.-S. Lipopolysaccharide-induced Notch signaling activation through JNK-dependent pathway regulates inflammatory response. J. Biomed. Sci. 2011, 18, 56. [CrossRef] [PubMed]

52. Degaki, K.Y.; Chen, Z.; Yamada, A.T.; Croy, B.A. Delta-like ligand (DLL)1 expression in early mouse decidua and its localization to uterine natural killer cells. PLoS ONE 2012, 7, e52037. [CrossRef] [PubMed]

53. Snodgrass, R.G.; Brüne, B. Regulation and Functions of 15-Lipoxygenases in Human Macrophages. Front. Pharmacol. 2019, 10. [CrossRef]

54. Singh, N.K.; Rao, G.N. Emerging role of 12/15-Lipoxygenase (ALOX15) in human pathologies. Prog. Lipid Res. 2019, 73, 28-45. [CrossRef] [PubMed]

55. Ghosh, M.; Tucker, D.; Burchett, S.; Leslie, C. Properties of the Group IV phospholipase A2 family. Prog. Lipid Res. 2006, 45, 487-510. [CrossRef] [PubMed] 
56. Földi, J.; Kulcsár, M.; Pécsi, A.; Huyghe, B.; de Sa, C.; Lohuis, J.A.C.M.; Cox, P.; Huszenicza, G. Bacterial complications of postpartum uterine involution in cattle. Anim. Reprod. Sci. 2006, 96, 265-281. [CrossRef] [PubMed]

57. Salilew-Wondim, D.; Ibrahim, S.; Gebremedhn, S.; Tesfaye, D.; Heppelmann, M.; Bollwein, H.; Pfarrer, C.; Tholen, E.; Neuhoff, C.; Schellander, K.; et al. Clinical and subclinical endometritis induced alterations in bovine endometrial transcriptome and miRNome profile. BMC Genom. 2016, 17, 218. [CrossRef]

58. Kim, T.H.; Yoo, J.-Y.; Choi, K.-C.; Shin, J.-H.; Leach, R.E.; Fazleabas, A.T.; Young, S.L.; Lessey, B.A.; Yoon, H.-G.; Jeong, J.-W. Loss of HDAC3 results in nonreceptive endometrium and female infertility. Sci. Transl. Med. 2019, 11, eaaf7533. [CrossRef]

59. Choe, C.; Park, J.-W.; Kim, E.-S.; Lee, S.-G.; Park, S.-Y.; Lee, J.-S.; Cho, M.-J.; Kang, K.R.; Han, J.; Kang, D. Proteomic analysis of differentially expressed proteins in bovine endometrium with endometritis. Korean J. Physiol. Pharmacol. 2010, 14, 205-212. [CrossRef]

60. Park, H.J.; Kim, Y.S.; Yoon, T.K.; Lee, W.S. Chronic endometritis and infertility. Clin. Exp. Reprod. Med. 2016, 43, 185-192. [CrossRef]

61. Doğan-Ekici, A.I.; Usubütün, A.; Küçükali, T.; Ayhan, A. Xanthogranulomatous endometritis: A challenging imitator of endometrial carcinoma. Infect. Dis. Obstet. Gynecol. 2007, 2007. [CrossRef] [PubMed]

62. Himes, K.P.; Handley, D.; Chu, T.; Burke, B.; Bunce, K.; Simhan, H.N.; Peters, D.G. Comprehensive analysis of the transcriptional response of human decidual cells to lipopolysaccharide stimulation. J. Reprod. Immunol. 2012, 93, 17-27. [CrossRef] [PubMed]

63. Momtazi, A.A.; Banach, M.; Sahebkar, A. PCSK9 inhibitors in sepsis: A new potential indication? Expert Opin. Investig. Drugs 2017, 26, 137-139. [CrossRef] [PubMed]

64. Paciullo, F.; Fallarino, F.; Bianconi, V.; Mannarino, M.R.; Sahebkar, A.; Pirro, M. PCSK9 at the crossroad of cholesterol metabolism and immune function during infections. J. Cell. Physiol. 2017, 232, 2330-2338. [CrossRef] [PubMed]

65. Carroll, R.G.; Zasłona, Z.; Galván-Peña, S.; Koppe, E.L.; Sévin, D.C.; Angiari, S.; Triantafilou, M.; Triantafilou, K.; Modis, L.K.; O'Neill, L.A. An unexpected link between fatty acid synthase and cholesterol synthesis in proinflammatory macrophage activation. J. Biol. Chem. 2018, 293, 5509-5521. [CrossRef]

66. Shiozawa, T.; Shih, H.-C.; Miyamoto, T.; Feng, Y.-Z.; Uchikawa, J.; Itoh, K.; Konishi, I. Cyclic Changes in the Expression of Steroid Receptor Coactivators and Corepressors in the Normal Human Endometrium. J. Clin. Endocrinol. Metab. 2003, 88, 871-878. [CrossRef]

67. Hall, A. Chapter 19 The role of ras in signal transduction. In Principles of Medical Biology; Elsevier Inc.: Amsterdam, The Netherlands, 1997; Volume 7, pp. 451-468.

68. Lu, J.; Teh, B.K.; Wang, L.; Wang, Y.; Tan, Y.S.; Lai, M.C.; Reid, K.B.M. The classical and regulatory functions of C1q in immunity and autoimmunity. Cell. Mol. Immunol. 2008, 5, 9-21. [CrossRef]

69. Yanai, H.; Ban, T.; Taniguchi, T. Essential role of high-mobility group box proteins in nucleic acid-mediated innate immune responses. J. Intern. Med. 2011, 270, 301-308. [CrossRef]

70. Yehia, L.; Jindal, S.; Komar, A.A.; Eng, C. Non-canonical role of cancer-associated mutant SEC23B in the ribosome biogenesis pathway. Hum. Mol. Genet. 2018, 27, 3154-3164. [CrossRef]

71. Wang, Y.; Hu, T.; Wu, L.; Liu, X.; Xue, S.; Lei, M. Identification of non-coding and coding RNAs in porcine endometrium. Genomics 2017, 109, 43-50. [CrossRef]

72. Noh, K.T.; Jung, I.D.; Cha, G.S.; Han, M.-K.; Park, Y.-M. Platelet-activating Factor Mediates Endotoxin Tolerance by Regulating Indoleamine 2,3-Dioxygenase-dependent Expression of the Suppressor of Cytokine Signaling 3. J. Biol. Chem. 2017, 292, 3290-3298. [CrossRef] [PubMed]

73. Broeke, S.W.T.; Klift, H.M.V.; Tops, C.M.J.; Aretz, S.; Bernstein, I.; Buchanan, D.D.; de la Chapelle, A.; Capella, G.; Clendenning, M.; Engel, C.; et al. Cancer Risks for PMS2-associated lynch syndrom. J. Clin. Oncol. 2018, 36, 2961-2968. [CrossRef] [PubMed]

74. Gao, C.; Wang, Y.; Broaddus, R.; Sun, L.; Xue, F.; Zhang, W. Exon 3 mutations of CTNNB1 drive tumorigenesis: A review. Oncotarget 2018, 9, 5492-5508. [CrossRef] [PubMed]

75. Bazak, L.; Haviv, A.; Barak, M.; Jacob-Hirsch, J.; Deng, P.; Zhang, R.; Isaacs, F.J.; Rechavi, G.; Li, J.B.; Eisenberg, E.; et al. A-to-I RNA editing occurs at over a hundred million genomic sites, located in a majority of human genes. Genome Res. 2014, 24, 365-376. [CrossRef] 
76. Chen, J.-Y.; Peng, Z.; Zhang, R.; Yang, X.-Z.; Tan, B.C.-M.; Fang, H.; Liu, C.-J.; Shi, M.; Ye, Z.-Q.; Zhang, Y.E.; et al. RNA Editome in Rhesus Macaque Shaped by Purifying Selection. PLoS Genet. 2014, 10, e1004274. [CrossRef]

77. Funkhouser, S.A.; Steibel, J.P.; Bates, R.O.; Raney, N.E.; Schenk, D.; Ernst, C.W. Evidence for transcriptome-wide RNA editing among Sus scrofa PRE-1 SINE elements. BMC Genom. 2017, 18, 360. [CrossRef]

78. Yang, Y.; Zhu, M.; Fan, X.; Yao, Y.; Yan, J.; Tang, Y.; Liu, S.; Li, K.; Tang, Z. Developmental atlas of the RNA editome in Sus scrofa skeletal muscle. DNA Res. 2019, 26, 261-272. [CrossRef]

79. Maekawa, R.; Taketani, T.; Mihara, Y.; Sato, S.; Okada, M.; Tamura, I.; Jozaki, K.; Kajimura, T.; Asada, H.; Tamura, H.; et al. Thin endometrium transcriptome analysis reveals a potential mechanism of implantation failure. Reprod. Med. Biol. 2017, 16, 206-227. [CrossRef]

80. Balasubramaniam, S.; Choy, Y.S.; Talib, A.; Norsiah, M.D.; van den Heuvel, L.P.; Rodenburg, R.J. Infantile Progressive Hepatoencephalomyopathy with Combined OXPHOS Deficiency due to Mutations in the Mitochondrial Translation Elongation Factor Gene GFM1. In JIMD Reports; Springer: Berlin/Heidelberg, Germany, 2011; Volume 5, pp. 113-122.

81. Mikołajczyk, A.; Gonkowski, S.; Złotkowska, D. Modulation of the main porcine enteric neuropeptides by a single low-dose of lipopolysaccharide (LPS) Salmonella Enteritidis. Gut Pathog. 2017, 9, 73. [CrossRef]

82. Mikołajczyk, A.; Złotkowska, D. Subclinical lipopolysaccharide from Salmonella Enteritidis induces neuropeptide dysregulation in the spinal cord and the dorsal root ganglia. BMC Neurosci. 2019, 20, 18. [CrossRef]

83. Andrews, S. FastQC: A Quality Control Tool for High Throughput Sequence Data. Babraham Bioinforma. 2010. Available online: http://www.bioinformatics.babraham.ac.uk/projects/fastqc (accessed on 1 January 2020).

84. Bolger, A.M.; Lohse, M.; Usadel, B. Trimmomatic: A flexible trimmer for Illumina sequence data. Bioinformatics 2014, 30, 2114-2120. [CrossRef] [PubMed]

85. Dobin, A.; Davis, C.A.; Schlesinger, F.; Drenkow, J.; Zaleski, C.; Jha, S.; Batut, P.; Chaisson, M.; Gingeras, T.R. STAR: Ultrafast universal RNA-seq aligner. Bioinformatics 2013, 29, 15-21. [CrossRef] [PubMed]

86. Pertea, M.; Pertea, G.M.; Antonescu, C.M.; Chang, T.-C.; Mendell, J.T.; Salzberg, S.L. StringTie enables improved reconstruction of a transcriptome from RNA-seq reads. Nat. Biotechnol. 2015, 33, 290-295. [CrossRef] [PubMed]

87. R Core Team R: A Language and Environment for Statistical Computing. Available online: http://www.Rproject.org/ (accessed on 1 February 2020).

88. Trapnell, C.; Roberts, A.; Goff, L.; Pertea, G.; Kim, D.; Kelley, D.R.; Pimentel, H.; Salzberg, S.L.; Rinn, J.L.; Pachter, L. Differential gene and transcript expression analysis of RNA-seq experiments with TopHat and Cufflinks. Nat. Protoc. 2012, 7, 562-578. [CrossRef] [PubMed]

89. Love, M.I.; Huber, W.; Anders, S. Moderated estimation of fold change and dispersion for RNA-seq data with DESeq2. Genome Biol. 2014, 15, 550. [CrossRef] [PubMed]

90. Robinson, M.D.; Mccarthy, D.J.; Smyth, G.K. edgeR: A Bioconductor package for differential expression analysis of digital gene expression data. Bioinforma. Appl. NOTE 2010, 26, 139-140. [CrossRef] [PubMed]

91. Reimand, J.; Arak, T.; Adler, P.; Kolberg, L.; Reisberg, S.; Peterson, H.; Vilo, J. g:Profiler-A web server for functional interpretation of gene lists. Nucleic Acids Res. 2016, 44, W83-W89. [CrossRef]

92. Ashburner, M.; Ball, C.A.; Blake, J.A.; Botstein, D.; Butler, H.; Cherry, J.M.; Davis, A.P.; Dolinski, K.; Dwight, S.S.; Eppig, J.T.; et al. Gene ontology: Tool for the unification of biology. Nat. Genet. 2000, 25, $25-29$. [CrossRef]

93. Kanehisa, M.; Furumichi, M.; Tanabe, M.; Sato, Y.; Morishima, K. KEGG: New perspectives on genomes, pathways, diseases and drugs. Nucleic Acids Res. 2017, 45, D353-D361. [CrossRef]

94. Wang, L.; Park, H.J.; Dasari, S.; Wang, S.; Kocher, J.-P.; Li, W. CPAT: Coding-Potential Assessment Tool using an alignment-free logistic regression model. Nucleic Acids Res. 2013, 41, e74. [CrossRef]

95. Kang, Y.J.; Yang, D.C.; Kong, L.; Hou, M.; Meng, Y.Q.; Wei, L.; Gao, G. CPC2: A fast and accurate coding potential calculator based on sequence intrinsic features. Nucleic Acids Res. 2017, 45, W12-W16. [CrossRef] [PubMed]

96. Wucher, V.; Legeai, F.; Hédan, B.; Rizk, G.; Lagoutte, L.; Leeb, T.; Jagannathan, V.; Cadieu, E.; David, A.; Lohi, H.; et al. FEELnc: A tool for long non-coding RNA annotation and its application to the dog transcriptome. Nucleic Acids Res. 2017, gkw1306. [CrossRef] [PubMed] 
97. Finn, R.D.; Mistry, J.; Tate, J.; Coggill, P.; Heger, A.; Pollington, J.E.; Gavin, O.L.; Gunasekaran, P.; Ceric, G.; Forslund, K.; et al. The Pfam protein families database. Nucleic Acids Res. 2010, 38, D211-D222. [CrossRef] [PubMed]

98. Griffiths-Jones, S. Rfam: An RNA family database. Nucleic Acids Res. 2003, 31, 439-441. [CrossRef]

99. Trincado, J.L.; Entizne, J.C.; Hysenaj, G.; Singh, B.; Skalic, M.; Elliott, D.J.; Eyras, E. SUPPA2: Fast, accurate, and uncertainty-aware differential splicing analysis across multiple conditions. Genome Biol. 2018, 19, 40. [CrossRef]

100. Shen, S.; Park, J.W.; Lu, Z.-X.; Lin, L.; Henry, M.D.; Wu, Y.N.; Zhou, Q.; Xing, Y. rMATS: Robust and flexible detection of differential alternative splicing from replicate RNA-Seq data. Proc. Natl. Acad. Sci. USA 2014, 111, E5593-E5601. [CrossRef]

101. Patro, R.; Duggal, G.; Love, M.I.; Irizarry, R.A.; Kingsford, C. Salmon provides fast and bias-aware quantification of transcript expression. Nat. Methods 2017, 14, 417-419. [CrossRef]

102. Veiga, D. Maser: Mapping Alternative Splicing Events to pRoteins. R Package Version 1.0.0. Available online: https://github.com/DiogoVeiga/maser (accessed on 1 February 2020).

103. Xie, Z.J.; Tseng, Y.-T.; Xing, Y. rmats2sashimiplot. Available online: https://github.com/Xinglab/ rmats2sashimiplot (accessed on 1 February 2020).

104. Wang, J.; Pan, Y.; Shen, S.; Lin, L.; Xing, Y. rMATS-DVR: rMATS discovery of differential variants in RNA. Bioinformatics 2017, 33, 2216-2217. [CrossRef]

105. McKenna, A.; Hanna, M.; Banks, E.; Sivachenko, A.; Cibulskis, K.; Kernytsky, A.; Garimella, K.; Altshuler, D.; Gabriel, S.; Daly, M.; et al. The Genome Analysis Toolkit: A MapReduce framework for analyzing next-generation DNA sequencing data. Genome Res. 2010. [CrossRef]

106. Wang, X.; Lu, P.; Luo, Z. GMATo: A novel tool for the identification and analysis of microsatellites in large genomes. Bioinformation 2013, 9, 541-544. [CrossRef]

107. Cingolani, P.; Platts, A.; Wang, L.L.; Coon, M.; Nguyen, T.; Wang, L.; Land, S.J.; Lu, X.; Ruden, D.M. A program for annotating and predicting the effects of single nucleotide polymorphisms, SnpEff. Fly Austin 2012, 6, 80-92. [CrossRef] [PubMed]

108. McLaren, W.; Gil, L.; Hunt, S.E.; Riat, H.S.; Ritchie, G.R.S.; Thormann, A.; Flicek, P.; Cunningham, F. The Ensembl Variant Effect Predictor. Genome Biol. 2016, 17, 122. [CrossRef] [PubMed]

109. Krzywinski, M.; Schein, J.; Birol, I.; Connors, J.; Gascoyne, R.; Horsman, D.; Jones, S.J.; Marra, M.A. Circos: An Information Aesthetic for Comparative Genomics. Genome Res 2009, 19, 1639-1645. [CrossRef] [PubMed]

110. Quinlan, A.R.; Hall, I.M. BEDTools: A flexible suite of utilities for comparing genomic features. Bioinformatics 2010, 26, 841-842. [CrossRef] [PubMed]

111. DREP: Database of RNA Editing in Pig. Available online: http://www.rnanet.org/editing/home.html (accessed on 4 May 2020).

112. Schmittgen, T.D.; Livak, K.J. Analyzing real-time PCR data by the comparative C(T) method. Nat. Protoc. 2008, 3, 1101-1108. [CrossRef]

(C) 2020 by the authors. Licensee MDPI, Basel, Switzerland. This article is an open access article distributed under the terms and conditions of the Creative Commons Attribution (CC BY) license (http://creativecommons.org/licenses/by/4.0/). 